University of San Diego

Digital USD

2004-05-01

\title{
Nobody's Ever Asked Me That Before: Middle School Students Talk about Motivation to Achieve in School Contexts
}

\author{
Erika Daniels EdD \\ University of San Diego
}

Follow this and additional works at: https://digital.sandiego.edu/dissertations

Part of the Leadership Studies Commons

\section{Digital USD Citation}

Daniels, Erika EdD, "Nobody's Ever Asked Me That Before: Middle School Students Talk about Motivation to Achieve in School Contexts" (2004). Dissertations. 868.

https://digital.sandiego.edu/dissertations/868

This Dissertation: Open Access is brought to you for free and open access by the Theses and Dissertations at Digital USD. It has been accepted for inclusion in Dissertations by an authorized administrator of Digital USD. For more information, please contact digital@sandiego.edu. 


\title{
Nobody's Ever Asked Me That Before: \\ Middle School Students Talk About Motivation to \\ Achieve in School Contexts
}

by

Erika Daniels

\begin{abstract}
A dissertation submitted to the faculty of
San Diego State University and the University of San Diego

in partial fulfillment of the requirements for the degree of Doctor of Education
\end{abstract}

\author{
Dissertation Committee: \\ Leif Fearn, Ed.D., SDSU \\ Nancy Farnan, Ph.D., SDSU \\ Robert Infantino, Ed.D., USD
}

May, 2004 
(C) Copyright by Erika Daniels, 2004

All Rights Reserved 
Abstract

The purpose of this study was to explore whether or not a connection exists between students' school contexts and their academic and social choices by listening to the voices of first year middle school students. The intent of this study was to provide teachers with a way to reconceptualize adolescents as learners. Research suggests that there are two distinct approaches to the study of motivation. Some researchers believe that motivation can be externally enacted through exams, assessments, and other accountability measures. Other researchers believe that motivation is internally generated through the relationships students build, through their beliefs about learning, and through their past successes and failures. Both approaches dominate discussions on student motivation and achievement.

This work represented students' voices in order to explore which approach to motivation led to a better understanding of students' reactions to middle school that, in turn, will allow teachers to create instructional contexts that encourage genuine engagement and academic achievement. The study accomplished its purpose by surveying, interviewing, and observing students in their first year of middle school and analyzing what they said 
influenced their decisions to engage in or to disengage from school learning experiences.

Data analysis identified themes that ran through the students' responses. By highlighting the voices of young adolescents, this study found that external factors influence internal motivation to achieve but cannot alone sustain it. Young adolescents wanted to be academically challenged by their teachers, but they also needed their coursework to be relevant to their immediate interests and needs. Being told that school was a preparation for some distant future was not a sufficient reason to work diligently. Students in this study relied heavily on their network of friends and family as they adjusted to their new school contexts, and teachers also influenced motivation through their teaching practices, interactions with students, and expectations for student success or failure. 
This is dedicated to all of the middle school

students who have not been able to tell their stories. 
Acknowledgements

In self reports of their process, many writers state that writing is a solitary and often lonely process. Writing this dissertation, indeed the entire doctoral journey, has proven to be the opposite experience. Although I have spent much time alone at my computer, I have been surrounded by the love and support of family members, friends, and colleagues. Without them, this work would not exist.

First I would like to thank the middle school students who shared their stories with me so honestly. Their willingness to take a risk with a complete stranger humbles me. I promise them that I will always work to privilege their voices in educational and political discussions. They deserve nothing less and always a little more.

Words of thanks cannot describe my gratitude to my family. My dad always said I could do anything I set my mind to-you've been right so far Dad! Thank you Mom and Dad for teaching me that diligent work, compassion, and ethical behavior must provide a foundation for anything I do. To my husband who has believed in me from the beginning, through the hard times, and even when I didn't believe in myself. Thank you Jason for being my best friend 
and always pushing me to be better than I ever thought I could be.

To my friends, thank you for your patience and your support. For four years, you listened to me ramble and always sounded interested. You never made me feel guilty for dropping out of sight. I promise that phone calls will be returned more quickly now! And to Janet, Laurie, Jill, and Annette, my colleagues at CSUSM, thank you for your endless encouragement and support.

And to the Critical Reading and Preparation group. Jen, Cindy, Mark, Willie, and Dina-what a journey! Your personal friendship and professional support is far and away the best gift this program has given me. You have taught me the true meaning of collegiality and friendship.

Thank you to Dr. Nancy Earnan and Dr. Robert Infantino for being part of my committee. You pushed me to be a better scholar and writer.

And finally to Dr. Leif Fearn. Thank you seems inadequate, but I hope that you truly understand the gifts that you have given me throughout this process. You have been a mentor who has supported me, challenged me, and helped me grow. I am a better writer, scholar, and person because of the strength of your character and the model that you provided. Thank you! 
Acknowledgments ............................... vii

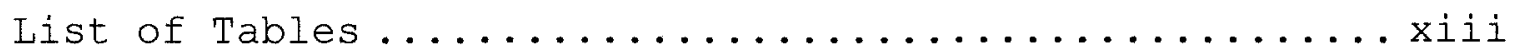

CHAPTER

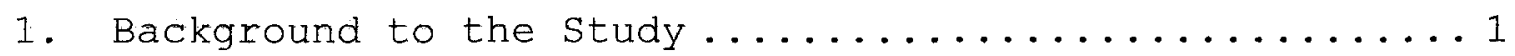

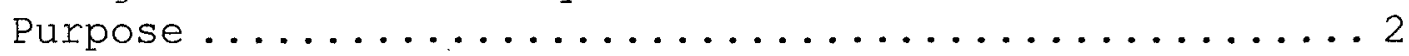



Environmental Contexts................

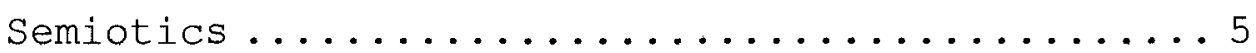

Interactions and Transformations ...........

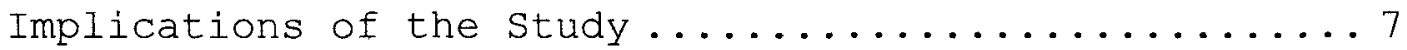



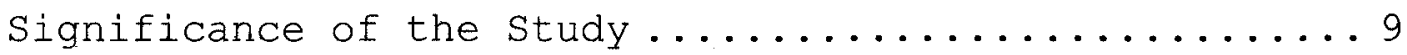

Academic Achievement in Middle School .........9

Long term ramifications of disengagement...... 11

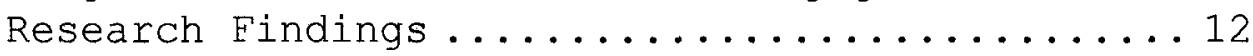

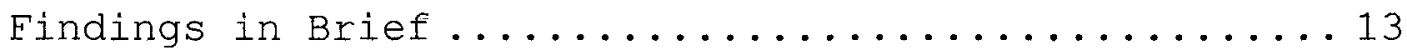

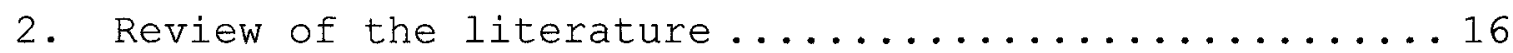

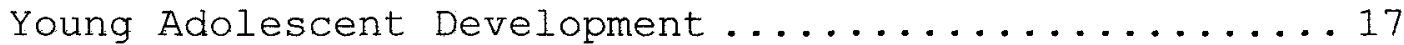

Physical Changes .................. 18

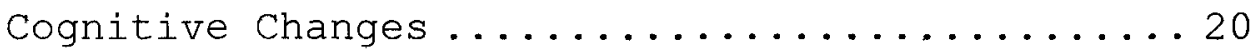

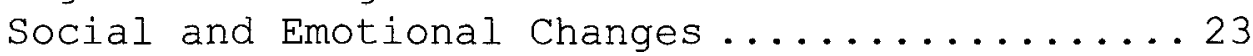

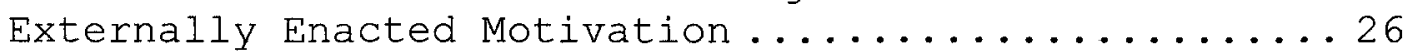

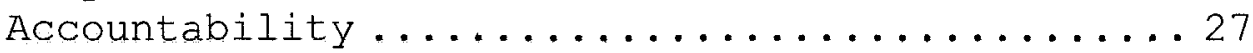

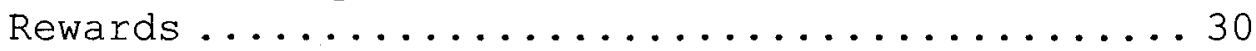

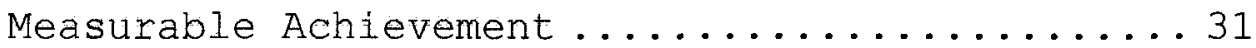

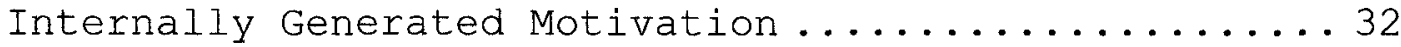

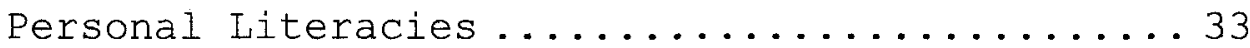

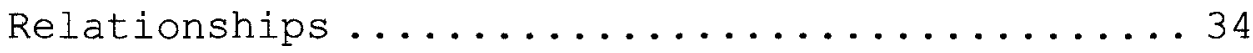

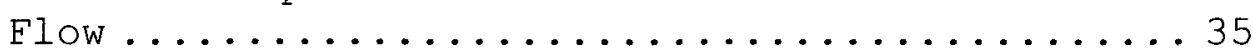

Autonomy vs. Control ........................ 37

Learning vs. Performance Orientations ........ 38

Implications for Research .................40

What we Still Need to Know .............40

3. Methodology ......................... 43

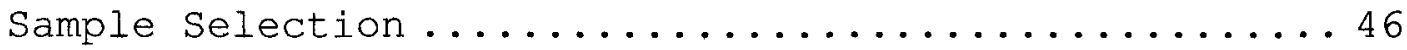

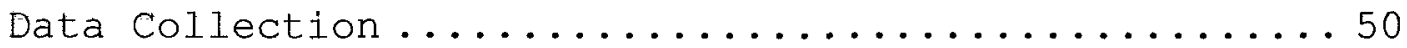

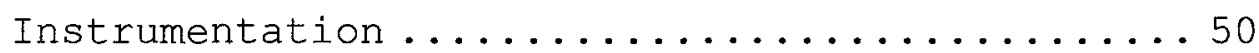

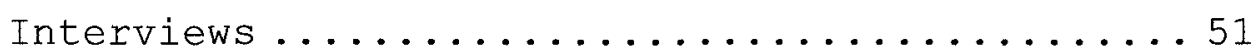

Observations ....................... 52 
Data Analysis .......................... 54

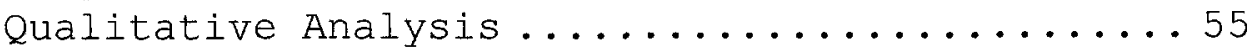

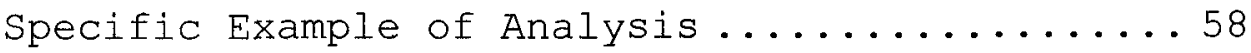

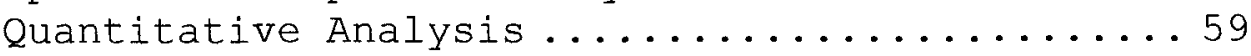

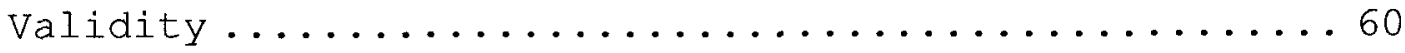

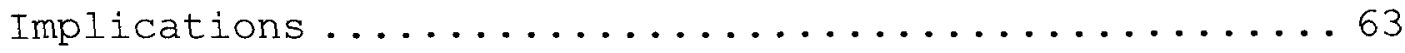



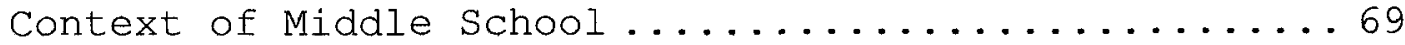

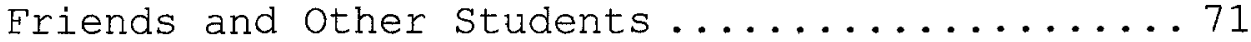

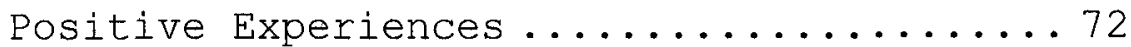

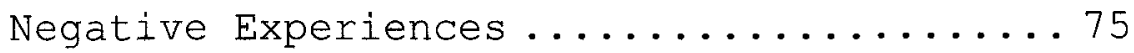

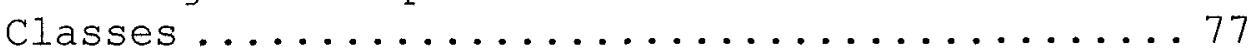

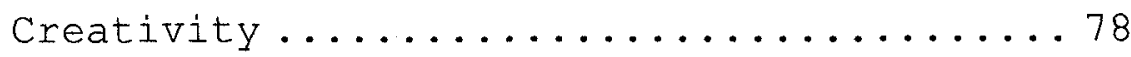

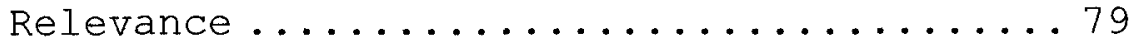

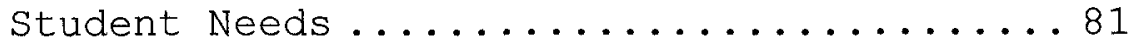

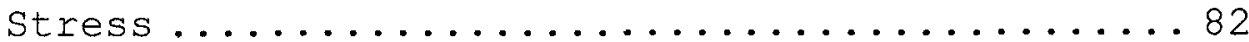

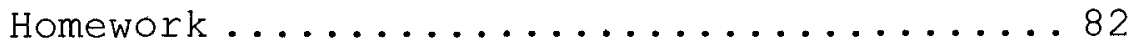

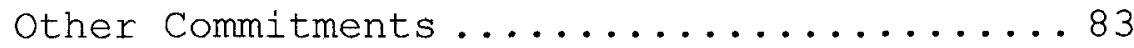

Balancing Assignments ............ 85

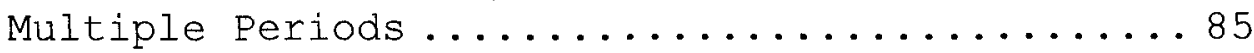

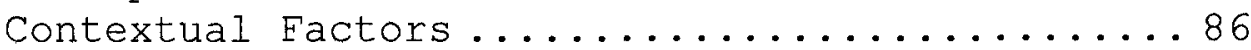

The Effects of Middle School Context.............89

Extracurricular Activities ............... 89

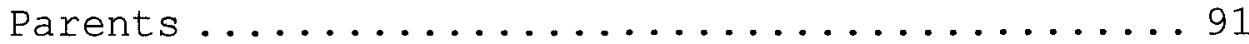

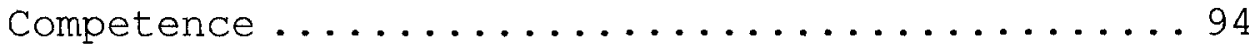

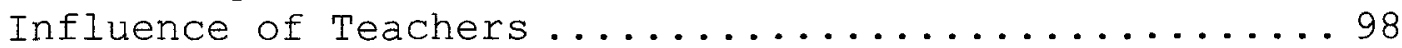

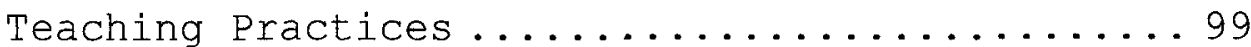

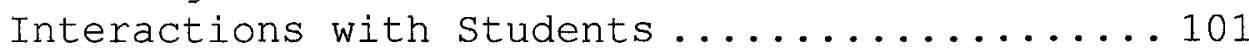

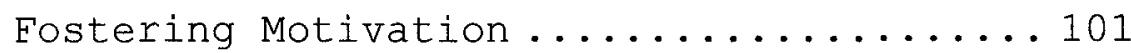

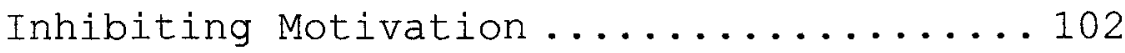

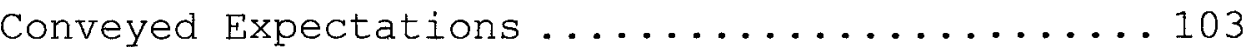

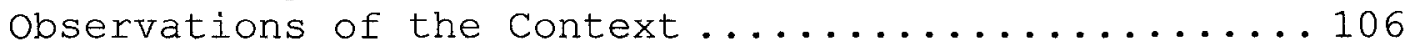

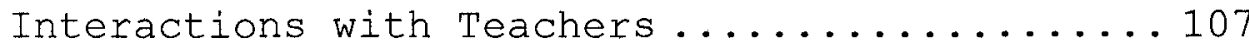

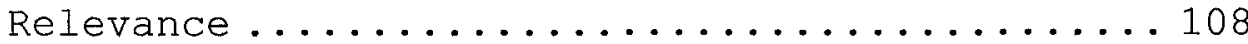

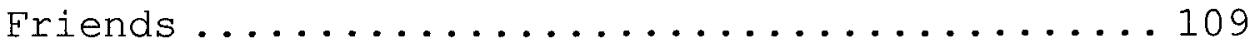

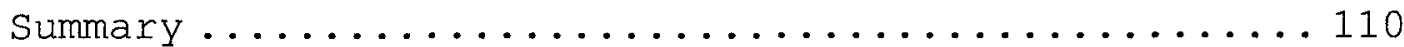

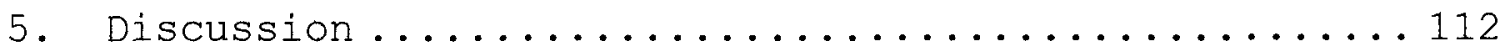

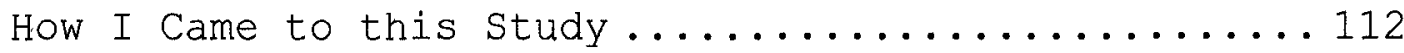

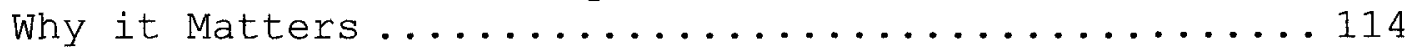

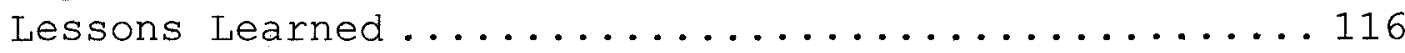

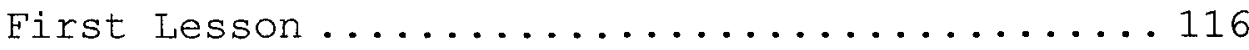

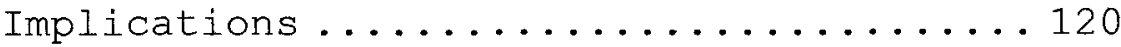

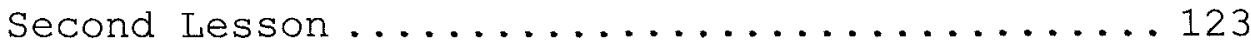

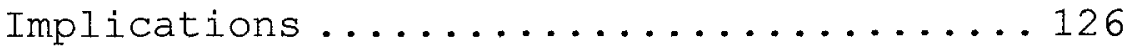

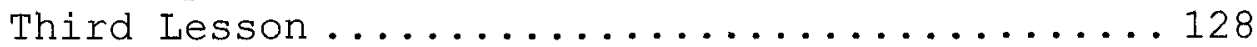

$\mathrm{xi}$ 


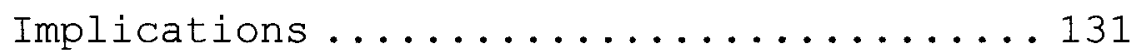

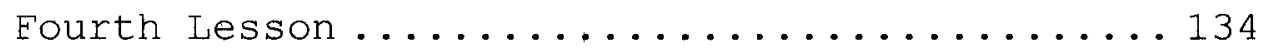

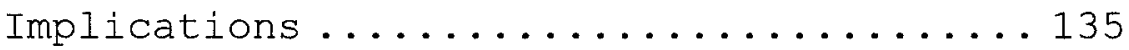

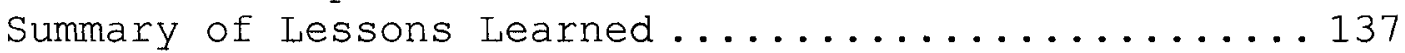

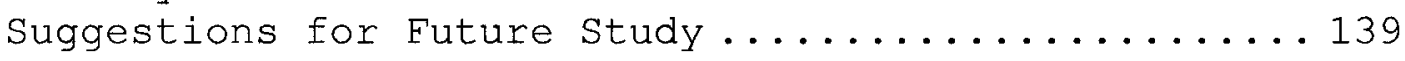

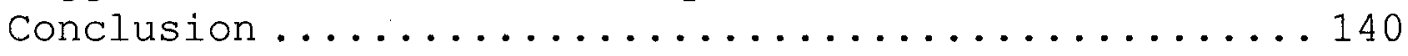

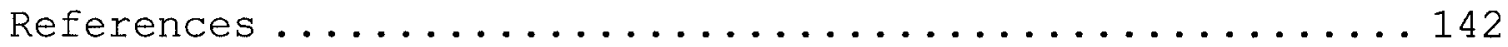

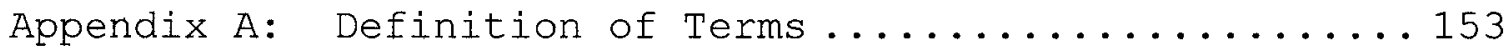

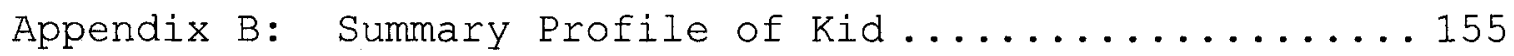

Appendix C: Initial Information Survey ........... 158

Appendix D: Interview Protocol ................ 160 


\section{List of Tables}

Table 1 Connection Between Theory and Method ........45

Table 2 Responses from Willow Glen and

Highlands Middle Schools ..............48

Table 3 Demographics of Respondents..............49

Table 4 Demographics of Interview Participants......68

Table 5 Average Responses According to

Grade Level ......................69

Table 6 Contextual Factors that Affect

Middle school students ...............71 
Chapter One

Background

I just stopped talking to the person who

motivated me to actually try and do my

work. This might sound stupid, but it hurts.

--Felipe, age 14

When Felipe wrote these words in his journal, he was a freshman at an alternative high school. His standardized test scores were exceptionally high, and his grades were exceptionally low. As his work in my English class that year indicated, he had the ability to achieve but continually chose not to exert the necessary effort. Much of the year, Felipe battled with his teachers, experimented with gang behavior, and frequently arrived at school high on drugs. Finally his attendance ceased entirely.

What I came to realize was that Felipe's motivation to achieve was tied directly to influential people in his life. When an assignment, task, or project struck a chord in Felipe, he worked tirelessly. His abilities were never in question as he proved able to accomplish anything to which he set his mind. His desire to engage in school, however, was inconsistent. Our work together was brilliant at times and devastating at others, but I never stopped trying to find the key to Felipe's motivation. Felipe and the countless students who were and are similar motivational mysteries are the impetus behind this study. 


\section{Purpose of study}

The actions in which humans engage are influenced by the contexts in which they occur (Hedegaard, Chaiklin, \& Jensen, 1998). As such, educational researchers, teachers, or administrators must examine institutional, social, historical, and individual factors (Wertsch, 1991) when they explore student motivation. There is a growing understanding that one's actions are dependent upon the expectations that a context has for behavior (Davydov, 1998; Doherty \& Mayer, 2003). Thus, it is important for teachers to understand this link in order to reach students like Felipe. People make decisions about how to act and what to say based on their knowledge of the setting and the expectations that exist within it (Gee, 1999). These expectations influence both internal and external motivation.

This study focuses on the position that motivation is internally generated but influenced by the activities in which students engage (Csikszentmihalyi, 1990) and the conditions present in their learning environment (Gee, 1999; Wertsch, 1991). It is primarily useful for teachers of reluctant learners-those students who are able to achieve academically but consistently do not demonstrate this ability for a variety of reasons. The purpose of this qualitative study was to explore whether a connection exists between the school contexts and the academic and social choices of students in their first year of middle school. Since external factors do appear to influence internal 
motivation (as will be shown in chapters four and five), this study will provide teachers with a way to reconceptualize adolescents as learners.

\section{Conceptual Framework}

Sociocultural theory views activity as a dynamic process that depends upon social interactions and communication (Hedegaard, Chaiklin, \& Jensen, 1998). It is impossible, therefore, or at the very least undesirable, to separate or isolate classrooms or hallways, teachers or students, when studying learning and teaching. The language used, the artifacts employed, and the actions taken by each member of a context contribute to the meaning that he/she constructs (Gee, 1999).

Students at the beginning of their middle school experience must learn what speech and which actions will identify them as participants in their new school. For too many students, however, this understanding is not intrinsic or automatic. Teachers' anecdotal records and research studies have found statistically significant achievement losses (Alspaugh, 1998), declines in student self-perception and self-esteem (Seidman, Allen, Aber, Mitchell, \& Feinman, 1994), and decreases in engagement (Daniels \& Arapostathis, in press) when students transition to middle school. In order to help students achieve academically, teachers must understand the lived experiences of those students. 
Environmental contexts

Context is "everything in the material, mental, personal, interactional, social, institutional, cultural, and historical situation" that influences the meaning people make (Gee, 1999, p. 54). The activities in which students engage, the interactions they have with peers and adults, and the physical characteristics of their learning environments all contribute to their motivation to learn and desire to engage.

Context, in sociocultural theory, consists of cultural artifacts such as language, technologies, social interactions, communication, and any other elements in the physical environment that influence learning, meaningmaking, and cognitive development (Wertsch, 1991). These artifacts allow people to identify with specific groups (Gee, 1999). For example, when in front of their classes, teachers often use formal language that requires respect and attention. When teachers are at home with their families, their language may be more casual to reflect the familiarity they feel in that context. Because of the ways in which meaning-making and understanding are shaped by social and cultural forces, a student's academic success or failure is influenced by the school context ( $\mathrm{Au}, 1997$ ) which makes sociocultural activity theory an important lens through which to explore motivation. 
Semiotics

Cultural artifacts are important in mediating human development and learning. Semiotic symbols, or cultural artifacts, are defined as language, numbers, gestures, and other symbol systems that individuals use during social interactions (Gee, 1999, pp. 82-83). An understanding of semiotics includes knowing "what and how different symbol systems and different forms of knowledge count" (Gee, 1999, p. 12).Because learning and meaning-making are inherently social, people's actions are mediated by the language they use, their expectations of others, and the tools available to them (Palincsar, 1998). This understanding will strengthen my data analysis as it will provide a lens through which to explore the students' stories.

Semiotic symbols are also used as mediational tools (Wertsch, 1991) that take their meaning from the actions in which they are employed. For example, report cards are a cause of emotional upheaval if students grades are low and their parents expect high achievement. The same grades might have no adverse effect on a student whose parents are not involved or do not believe that grades are important. Focusing on one artifact in isolation does not deepen our understanding of human development or learning because it is the interaction of those artifacts and social experiences that influences the quality of an activity or the reason the activity is undertaken (Stetsenko, 1998; Wertsch, 1991). 
By exploring the interaction between cultural artifacts (semiotics) and their use in context, as self-reported by the students in this study, it may be possible to better understand how those artifacts mediate students' desires to engage in school learning experiences.

Interactions and transformations

Sociocultural researchers believe that the use of cultural artifacts transforms actions (Wertsch, 1991) and helps participants construct meaning (Gee, 1999). Without language, gestures, and other symbols, contexts would not exist, and individuals could not interact. Cultures, therefore, would not grow or develop (Cole, 1996). Vygotsky (1978) believed that individual development is a product of context, not nature, because people internalize systems after repeated usage and reinforcement. When students engage in school or social activities, they use the interactions and cultural artifacts in ways that transform their cognitive abilities. Learning and development is transformed as students interact with teachers and peers through the use technology and language (Hedegaard, Chaiklin, \& Jensen, 1998).

Through activity, humans relate to their worlds (Fichtner, 1998). For children and adolescents, the bulk of their activities take place in or around schools, so their relationships to the world are heavily influenced by their school contexts. For many young adolescents, a tension between their needs and desires and the school's needs and 
desires begins to appear (Daniels \& Arapostathis, in press). As middle school students begin to realize "their increased powers of cognition and self-reflection" (McPhail, Pierson, Freeman, Goodman, \& Ayaapa, 2000, p. 45), they both want and need contexts that support their efforts at autonomy and identity formation (McPhail, et al, 2000).

If by listening to what the students have to say, teachers understand how to increase the quality of their interactions with students, middle school students might increasingly choose to engage and thus achieve at higher academic levels.

Implications of the study

Although the researchers cited here offer useful suggestions that are grounded in rigorous research, their work has been primarily conducted through an adult lens. Rarely have the students themselves been asked to describe their own lived experiences in school (see Cushman, 2003; Oldfather, 1994; Storz \& Nestor, 2003 for exceptions). This study contributes to existing research by using sociocultural theory as an analytical frame, while focusing on what the students themselves have to say about why they engage in or disengage from school activities.

This study adds to previously conducted research because of its focus on students in the first months of their first year in middle school. Most other researchers have talked to middle school students of all ages or to high school students or to elementary school students. Because 
this study focuses on students at the beginning of their middle school experience, it highlights the factors that contribute to smooth or difficult transitions. Another unique factor of this study is its use of multiple facets of data collection. By surveying a large sample, interviewing a smaller number, and observing yet another subset, this study triangulates the data in a way that will lend credence to the students' stories, voices, and insights.

Research focused on understanding the lived experiences of students in their first year of middle school (Cole, 1996) may inform the interactions that teachers have with their students. Instead of teaching students to play the game of school in order to achieve academically (Erickson, 1984), teachers may be able more effectively to provide an instructional context that will encourage genuine engagement and academic achievement.

\section{Research Questions}

The purpose of this study was to explore whether a connection exists between the school contexts and the academic and social choices of students in their first year of middle school. The intent of this work is to represent student voices in order to help teachers design instructional environments based on a better understanding of what learners say they need in order to engage in school.

The following research questions are posed for this study in order to create a more complete picture of the 
conditions necessary for students to achieve at high academic levels.

1. What elements are in the context of middle school that affect earned achievement and the desire to engage in school for adolescents?

2. Why do these contexts affect some adolescents and not others?

3. What roles do teachers and schools play in the creation of these contexts?

The research that contributed to the development of these questions will be further discussed in the review of the literature.

\section{Significance of the Study}

Academic achievement in middle school

Although some students are willing to exert effort in order to earn a high school diploma, others refuse to submit to what they view as the inflexibility of teachers and schools (Fair Test \& Massachusetts CARE, 2000; Fine, 1991). In today's political climate that emphasizes accountability through achievement on standardized assessments (www.cde.ca.gov/psaa), students who do not exert effort to achieve in school risk being labeled at-risk, learning disabled, or troublemakers. These labels stem from the belief that students who perform poorly in school do not care and will not be successful later in life (Amrein \& Berliner, 2003). High-stakes assessments such as the California High School Exit Exam and the CAT-6 allow 
decisions about children's futures to be made based on one standardized measure ( $R$. Kuhn, personal communication, May 10, 2003). When young adolescents score in the lower percentiles on standardized tests, they find subsequent scholastic opportunities limited.

The limitations on subsequent scholastic opportunities are most pronounced in the ways that students are assigned to classes in high school. Advanced and honors classes often accept only students with high standardized test scores and/or grades (R. Kuhn, personal communication, May 10, 2003), and colleges usually require advanced and honors classes and competitive test scores when considering applicants. Even if college is not an attractive option for some students, those who do not score well on standardized tests find themselves funneled into remedial classes although their true abilities might far exceed the course expectations. For example, students who attend an alternative school for ninth and tenth graders in a Southern California school district are not allowed into AP or honors classes when they transfer to the comprehensive high school, even if their abilities are documented by teacher reports and writing samples ( $R$. Kuhn, personal communication, May 10, 2003). These consequences contradict the motivation research which suggests that test scores and grades are not always indicators of a student's true ability (Dweck, 2000). If adolescents are not interested in the curriculum (McPhail, et al, 2000) or feel controlled by teachers (Deci, 
Koestner, \& Ryan, 2001), they may choose to disengage even if they have the ability to complete school tasks and to perform well on standardized tests (Daniels \& Arapostathis, in press).

Because negative consequences for school failure can hinder opportunities for adolescents, research that connects what students say they need with the existing motivation literature is imperative. Teachers may be more likely to listen to a combination of student and researcher voices because they face students on a daily basis. Long term ramifications of disengagement

Patterns of disengagement begun in middle school often continue into high school, and it appears that both low academic achievement and the reluctance to engage in classroom experiences often lead to students leaving high school without a diploma (www.sdcs.k12.ca.us/comm/extended_learning/connections/) . The community cannot afford to ignore disengaged and reluctant learners because individuals without high school diplomas constitute the majority of the prison populations and can earn $\$ 10,000$ less per year than their graduating peers (www.dropoutprevention.org). For the 2001-2002 school year, the California Department of education reported that 14,312 (10.9\%) high school seniors left school before graduating or attaining a legal equivalent (www.data1.cde.ca.gov/dataquest). 
Research findings

The high number of students who do not complete high school, and the emerging data that high-stakes assessments encourage students to leave school instead of working more diligently (Amrein \& Berliner, 2003; University of Chicago, 2004 ) suggest that traditional means of motivating teenagers through grades do not work for everyone. The likelihood of a student dropping out of high school can be traced to patterns of disengagement begun in middle school. If students struggle and are disengaged as sixth, seventh, and/or eighth graders, they may decide not to exert the effort necessary to attain a high school diploma. Preliminary research indicates that students must find reasons to engage before they are willing to exert effort (McPhail, et al, 2000), and that they must feel connected to their teachers (McCombs, 2002; Oldfather, 1994). These reasons to engage and the connections that are formed begin in middle school.

When students are intrinsically motivated, they do not work for grades or praise; rather, they work because they see their actions as autotelic or inherently worthwhile (Csikszentmihalyi, 1990; Deci, 1995). This internal motivation is influenced by the context of their schools. "It is not part of the human condition to be dependent on rewards" (Kohn, 1993, p. 91), but children grow more and more used to external gratification as schools use material rewards to manage behavior and encourage achievement. This 
reliance on point systems, pizza parties, and other extrinsic motivators is not necessary, however, because "children are more likely to be optimal learners if they are interested in what they are learning" (Kohn, 1993, p. 144).

The connection between the context of school and student engagement matters because research suggests that student engagement is connected to academic achievement. Shernoff, Schneider, and Csikszentmihalyi (1999) found that high quality learning occurs when student engagement in tasks is high. Csikszentmihalyi, Rathunde, and Whalen (1993) assert that students engage in learning primarily when they find enjoyment in the activities. These findings suggest that research geared toward understanding the conditions in middle school that influence student engagement will be informative for practitioners wanting to improve the academic achievement engagement of their students. Findings in Brief

Previous studies conducted with young adolescent participants (Csikszentmihalyi, et al, 1993; MCPhail, 2000; Shernoff, et al,1999) have offered concrete suggestions for educators who want to increase their students' engagement. When Csikszentmihalyi and his colleagues (1993) studied talented teenagers, they found that adolescents engage in school activities that are enjoyable and provide opportunities for in-depth study. McPhail and her colleagues (2000) found that sixth graders are most likely to participate when curriculum matches their interests. 
Similarly, Shernoff and his colleagues (1999) found that students are most engaged when participating in discussions, group work, and other interactive activities. I believe that the findings of this study contribute to this body of literature and provide insights into what middle school students need in order to achieve academically and thrive emotionally.

Existing research suggests patterns that contribute to students' decisions to engage or not engage in school learning experiences. For example, Smith and Wilhelm (2002) found that many students did not feel that their teachers valued literate behaviors such as discussing movie reviews or searching for information on the Internet. This disconnect caused many of the students in their study to disengage from school learning experiences. Pace (2003) found that the stories teachers and students share in class instruct others as to what beliefs and actions will be acceptable in the class culture. Moje (2000) found that by modeling only certain types of writing genres, teachers set "the norms for socially acceptable topics" (p. 43). oldfather (1994) asked fifth graders when and why they felt motivated for literacy learning. They repeatedly told her that they were not motivated when they were unable to complete assignments. Cushman (2003) worked with high school students who told her that teachers needed to take the time to get to know their students as individuals. 
The examples cited here suggest that teachers use literacy in the classroom in order to construct contexts for learning. When teachers value what students bring to school, the contexts of their classroom support and encourage engagement in school learning experiences. Because the students in this study voiced similar experiences, I believe that the findings extend a powerful invitation to think deeply about what teachers and administrators can do to ensure that their middle schools invite and foster motivation and achievement for all students. 


\section{Chapter Two \\ Review of the Literature}

Educators and researchers who study motivation and academic achievement often approach their work from two distinct theoretical standpoints. Some, who believe that teachers can make students motivated, hold that by implementing higher standards and holding teachers accountable for measurable student achievement, students will be more motivated and learn more (Gratz, 2000; Lewis; 1995). Others, who believe that motivation is internally generated, believe that the desire to engage is influenced by external factors but that true motivation must come from within (Csikszentmihalyi, 1990; Dweck, 2000). The supporting literature for each standpoint will be discussed in order to explain why the latter belief informs this study.

Because this study focuses on the motivation and achievement of middle school students specifically, it is also important to understand their unique emotional, physical, and cognitive characteristics. Children between the ages of 11 and 14 are known to educators, researchers, and administrators as young adolescents (Stevenson, 2002), and they undergo more physical, cognitive, emotional, and social changes during that time period than at any other time in their lives with the exception of infancy (Eccles \& Wigfield, 1997). Because these changes usually occur at the same time they are transitioning to middle school, understanding what transformations occur and how they affect 
the actions and emotions of students is imperative for teachers wanting to create motivating learning environments. In this chapter I will describe the primary characteristics of young adolescents as well as the research that supports both theoretical standpoints of motivation discussed above. Young Adolescent Development

Young adolescents experience distinct social, emotional, physical, and cognitive developmental changes that usually begin as they enter middle school which means they are adjusting to the changes at the same time they are transitioning to a new environment. Since motivation is influenced by the "fit between the characteristics individuals bring to their social environments and the characteristics of these social environments" (Eccles \& Wigfield, 1997, p. 22), it is imperative that middle school educators possess a thorough understanding what those characteristics are. Teachers cannot make students motivated nor can they control the many outside factors that affect motivation, but they can create environments that will mediate those external influences and support their students' motivation (Anderman \& Midgley, 1997). By focusing on what young adolescents need, want, worry about, and celebrate, educators are better able to establish motivating and supportive learning environments. Creating such environments is useful, even imperative, because research suggests that when instructional environments change, students' experiences, behavior, and interactions also 
change (Smith \& Wilhelm, 2002). Since middle school is traditionally a time during which students experience many changes, it is important to continue this research to ascertain what impact context really does have on motivation and achievement. This section will identify the specific developmental characteristics-physical, cognitive, social, and emotional-unique to young adolescents. Physical Changes

Young adolescents begin to develop sex characteristics, experience growth spurts, and become fertile (Eccles \& Wigfield, 1997). These changes in the body in general and hormone production in particular-typically known as pubertybegin for young adolescents at varying times. Girls typically show physical signs of adolescence 18-24 months earlier than boys (Eccles \& Wigfield, 1997). Since girls enter puberty earlier than boys, this means they are more likely to be coping with these changes at the beginning of their transition to middle school while boys are more likely to enter puberty toward the middle of their middle school experience. Regardless of the exact moment young adolescents enter puberty, it is important for teachers to recognize that the physical changes wrought during this time will have an impact on students' desires and/or abilities to engage in school learning experiences as their focus shifts to exploring and trying to gain control of their new interests and priorities. 
Although puberty usually begins between the ages of 11 and 14, early and late maturing children are also common. This matters to educators because of the educational and social ramifications of looking, acting, or being "different" in middle school. Early-maturing boys experience prestige among their friends and a more positive selfconcept, but early-maturing girls have been found to marry earlier and to have less education than their peers (Eccles \& Wigfield, 1997). Conversely, late-maturing boys tend to demonstrate attention-seeking behaviors in order to compensate for what they feel are physical deficiencies, while late-maturing girls often have higher academic achievement (Eccles \& Wigfield, 1997). Although these are not inevitable consequences, the timing of maturation does influence the social dynamics that exist in middle school. When educators understand and are prepared for the physical changes that young adolescents will undergo, they can support the students' views of themselves, help them develop stronger self-concepts, and encourage them to engage in academic learning experiences (Mizelle \& Mullins, 1997). In other words, middle schools can create structures that support students during the tumultuous changes that puberty brings .

Because of the increased hormone production, young adolescents have very real physical needs that must be met in order for engagement and therefore real learning to occur. When they are given the opportunity to be physically 
active in the classroom and are not required to sit still for long periods of time, middle school students are able to concentrate more fully on the material being taught (Stevenson, 2002). Additionally the increased hormone production actually changes young adolescents' sleep habits so that their desire to stay up late at night and to sleep late into the morning is primarily a result of biology, not obstinance (Stevenson, 2002). Understanding these physical realities allows effective middle level educators to create learning environments that take young adolescents' needs into account and teach them how to cope in order to be successful in school.

Cognitive Changes

Young adolescents do not just experience physical changes, but their intellectual, or cognitive, capabilities are also rapidly developing in complexity. Although their cognitive abilities increase steadily, "they need a lot of experience exercising these skills before they can use the skills efficiently" (Eccles \& Wigfield, 1997, p. 18) because of the dichotomy between their existing and potential abilities. Childhood is characterized by a focus on concrete thinking where there is only one answer or perspective, but adolescents begin to think abstractly and to view situations from multiple perspectives. Because this is new behavior for young adolescents, they need teachers to help them refine their abstract thinking skills and teach them to use them to 
the best of their ability (Eccles \& Wigfield, 1997;

Stevenson, 2002).

Young adolescents crave opportunities to make their own decisions, to help others, to see the purpose in what they are being asked to do, and to have increased choices. As they move from thinking that there is always one right answer to realizing that issues often can be approached from multiple perspectives, young adolescents also want to exercise more control over their own lives (Lipka, 1997). Sometimes they exert this desire by choosing not to participate in class, not because they are shy, but because it is one way to maintain control over their lives (Jones \& Gerig, 1994). One way to help them see that they do have control is to teach them that their thinking has an immediate and direct impact on their learning (McCombs, $2002)$

Although they both desire and demand the freedom to make their own decisions, young adolescents still need support and guidance from their parents and teachers (Perlstein, 2003). As they explore critical issues and wrestle with complex problems, young adolescents continually refine the cognitive abilities that will serve them throughout their lives (www.nmsa.org). Ironically, many middle school classrooms offer "fewer opportunities for student decision-making, choice, and self-management" (Eccles \& Wigfield, 1997, p. 24) which may contribute to the decline in achievement and engagement that many middle 
school students experience. They want to put their increasingly complex cognitive abilities to the test without worrying that they will face ridicule or derision from students and teachers. "Showing respect for students" decisions, lives, and relationships is key, even if these diverge from what we might wish for them" (Hinchman, Alvermann, Boyd, Brozo, \& Vacca, 2003/2004).

This is not to say that young adolescents only want "easy" work or do not want to be challenged. The studies that have talked to middle school students reveal that they do want to be challenged by their teachers and the curriculum while also wanting to assume responsibility for their learning (Storz \& Nestor, 2003), and they want teachers to recognize that they bring "interests and expertise from outside of school to the table" (Smith \& Wilhelm, 2002, p. 99). Curriculums that allow students some degree of choice in how they focus their learning or in the manner in which that learning is demonstrated can still be rigorous and challenging, but students are not empty vessels and want to incorporate their own interests and skills into the school curriculum (Smith \& Wilhelm, 2002).

Young adolescents, even in their first year of middle school, are fully capable of "reliably describe(ing) their interests in learning" and "the use of these interests in the design of the curriculum can increase student engagement in learning" (McPhail, Pierson, Freeman, Goodman, \& Ayappa, 2000 , p. 60). When students are empowered to learn, engaged 
intellectually, and helped to see how skills learned in school apply to their real lives, they are much more likely to exert the effort necessary to realize high academic achievement (NMSA, 2003). In other words, constructing knowledge is more desirable than merely consuming information because it meshes with their desires to make their own decisions and to see the purpose in what they are being asked to do. Curriculums that operate with this belief are more responsive to the cognitive needs of young adolescents.

Social and Emotional Changes

While young adolescents' reasoning skills and cognitive capabilities are rapidly increasing in complexity, they are also undergoing significant social and emotional development. Responsive middle schools understand that these other changes must also be acknowledged and understood because "achieving academic success is highly dependent upon their other developmental needs being met" (NMSA, 2003, p. 3). When children transition from elementary to middle school, they experience more than just a change in their physical environments. The social and emotional of hallmarks of young adolescence-increased dependence on peer approval, need for social acceptance, a struggle to find individual identities-can be exacerbated by the structure of middle schools themselves (www.nmsa.org). "Increases in student population, departmentalization, and ability grouping" often work in opposition to young adolescents' social and 
emotional needs for individualized attention as they search for what matters to them and what they stand for (Mizelle \& Mullins, 1997, p. 305). When teachers create instructional environments that work in concert with the needs of young adolescents, they are ensuring that the extrinsic variables in the context of middle school foster intrinsic motivation. Young adolescents need to understand the reasons they are being asked to complete tasks, and they want to see that their work matters in a larger context (Perlstein, 2003). Meaningful tasks increase the likelihood that students will engage because they will see the relevance and feel connected to others. "Youth benefit when they see themselves as able-as having something to contribute to the conversations about content being learned" (Hinchman, et al, $2003 / 2004)$. Social confidence increases which supports internal motivation. Because of their increasing intellectual skills, young adolescents are not as likely to acquiesce to teachers' demands or to believe that work matters simply because the teacher says so. They need to see the meaning for themselves (Daniels \& Arapostathis, in press). Since middle school is a period when demands on children's time increase dramatically, many students want to be allowed to determine "how to allocate their own limited resources of attention" (Csikszentmihalyi, Rathunde, \& Whalen, 1993, p. 42).

Because adolescence is a time when people work to determine what their identities are and what they stand for, 
middle school students are extremely aware of how others perceive them (Lipka, 1997). They are struggling to preserve their sense of self and to maintain positive self-esteem at the same time they are trying to fit in and find their niche. These goals work at cross purposes if young adolescents feel they are seen as differing from the mainstream in terms of their wants, needs, or abilities (Lipka, 1997). Although they tend to push adults away in their quest to develop independence, young adolescents also want and need to engage with positive adult role models during these tumultuous times (Perlstein, 2003). As they struggle to find their emotional and social places in the world, the students learn from the relationships that they build with the adults around them. They learn from the behavior of their teachers and from the implicit lessons"the way adults treat each other, set priorities, and make decisions" (NMSA, 2003, p. 11)-what behaviors are desired and/or rewarded in society. As young adolescents work through the substantive emotional changes, they increasingly want and need guidance in making their own moral and social choices.

Synthesis

Educators and researchers know a great deal about the physical, cognitive, social, and emotional changes that young adolescents undergo. Educators also know that in middle school, children form "the attitudes, values, and habits of mind that will largely direct their behavior as 
adults" (NMSA, 2003, p. 1). As such, teachers cannot discount or ignore these characteristics but instead must focus on creating environments that mediate them and teach young adolescents coping skills to deal with them. In order to do this, we must understand the role that schools play in both exacerbating and ameliorating the conditions. The students in this study provide insights into this role, and knowledge of the two theoretical standpoints on motivation provide additional information for educators.

\section{Externally Enacted Motivation}

Many people believe that external rewards such as pizza parties, grades, money, etc. cause students to work more diligently in school (Kohn, 1993). By offering rewards, teachers try to increase their students' engagement. This belief that motivation can be externally enacted is the foundation on which the standards and accountability movements are predicated. The standards movement began as a push for equity because the achievement gap between students in various economic groups was a major public concern (Gratz, 2000). Supporters believed that students simply needed an extra push to work more diligently so establishing higher expectations for everyone would increase motivation thereby ensuring the achievement of all students (Gratz, 2000). Once standards were in place in most states across the nation, proponents then began to look for ways to identify whether the external push was having the desired effect on motivation as measured by student achievement. If 
achievement did not increase, proponents demanded that students and their teachers be held accountable (Thompson, 2001). This focus on accountability was an unintended consequence of the standards movement that has influenced the way many politicians, educators, and community members think about motivation.

When people believe that motivation can be externally enacted, they also assert that disengaged students need only to be pushed harder in order to re-engage in school. If high standards are enacted, then students will begin to achieve at higher levels regardless of the underlying issues or reasons for their initial disengagement (Gratz, 2000). There is debate over whether this approach to motivation results in the desired increase in achievement (e. g. Amrein \& Berliner, 2002, 2003; Neil1, 2003). Some evidence suggests that, without linking standards to funding, school safety, equitable distribution of resources, and other school improvement plans, the achievement gap between high and low achievers will not be breached (Berube, 1996). Merely demanding higher scores without a commensurate increased emphasis on teaching for deeper thinking and sustained learning will not influence student motivation and achievement (Neill, 2003). If students do not see the value in working toward higher achievement, they will not. Accountability

Because the impetus for the standards movement was to increase academic achievement by implementing higher 
expectations, teachers then needed to demonstrate that their students had indeed met the state-imposed goals. Thus began the emphasis on high-stakes, standardized tests. By holding teachers accountable for student performance on state tests, proponents hoped that achievement would rise because student motivation would increase (Thompson, 2001). They believed that if the teachers and students were faced with rewards or punishments (external motivators) based on student performance, both groups would be inclined to work more diligently (Gratz; 2000; Neill, 2003).

The actual result has been that low-achieving students are disengaging to such an extent that many leave school before obtaining a high school diploma (Fair. Test \& Massachusetts CARE, 2000; Gratz, 2000). One reason is that without extra support to meet higher expectations and a reason to engage in more difficult tasks, students do not see the point of exerting extra effort (Gratz, 2000). Another is that some students who work hard but still fail will leave school in order to protect their feelings of self-worth (Covington, 1992; Fair Test \& Massachusetts CARE, 2000). Although context (e. g. teacher/student interactions and the physical environment) does matter in terms of enhancing motivation, the aftermath of the emphasis on highstakes tests suggests that a desire to engage in school cannot be entirely externally generated. Neither positive nor punitive consequences alone result in increased academic achievement but can, in some cases, encourage students to 
leave school early (Amrein \& Berliner, 2003). Existing literature suggests that external forces contribute to the desire of students to engage or not engage in school, but only in regards to how those forces influence their internal drive (Deci, 1995; Smith \& Wilhelm, 20002).

The pressure to improve teaching and learning and to increase student achievement has turned an educational issue into a political one. The impetus for the standards movement was the belief that providing a high quality education to all students is both morally and economically imperative (Thompson, 2001). When high stakes tests are emphasized, however, teaching mastery of lofty standards morphs into teaching students how to take tests (Valencia \& Wixson, 2001). "Instructional time is shifted to the curriculum areas that will appear on the tests" (Amrein \& Berliner, 2003, p. 34), and schools often emphasize drill activities and other tasks designed to improve test performance (Amrein \& Berliner, 2003).

Research does not demonstrate that a commensurate increase in academic achievement results from an increased focus on test performance (Valencia \& Wixson, 2001). On the contrary, researchers have found that scores on the SAT, ACT, and NAEP (all norm-referenced, nationally administered, standardized tests) in states with high-stakes exams actually decrease (Amrein \& Berliner, 2003). These studies suggest that fostering motivation and achievement requires more than merely an increase in external pressure. 
Rewards

Rewarding students for their engagement and/or achievement rarely fosters intrinsic motivation; the opposite effect usually occurs (Deci, 1995; Lepper \& Greene, 1978). Because a basic human need is to feel competent and autonomous, student intrinsic motivation to engage in a task diminishes if they feel that the engagement is a means to some ulterior end instead of being valuable in itself (Deci, Koestner, \& Ryan, 2001). This means that when pizza parties are offered to the student who reads the most books or a movie is offered as a reward for good behavior with the substitute, students learn to read books because reading leads to pizza and to behave for the substitute because good behavior leads to movies. Instead of engaging in an activity because of its inherent pleasure or importance, students learn to see engagement as a means to an end. "If teachers. - .emphasize the value of academic accomplishment in terms of the rewards it will bring, students' interest in what they are learning will almost certainly decline" (Kohn, 1993, p. 148).

Traditional schooling fosters this orientation through its reliance on grades, points, and other rewards. As students' reasons for engagement change, the joy from engaging in learning tasks loses potency (Deci, 1995). Consequently, when rewards in a classroom disappear, the students may not see a reason to perform a task or to 
attempt to achieve. Since extrinsic rewards are bestowed by someone other than the student him/herself, that person becomes a stimulus for reward and thus the activity. The external agent becomes the necessary cue for the desired behaviors which defeats the initial purpose behind offering the reward (Stipek, 1998). In other words, the reasons that the rewards are offered have an impact on student decisions to engage or not engage.

Measurable Achievement

Standards and high-stakes tests are two very different topics that have become joined in the public's mind. When asked about the standards, teachers and community members alike respond with their opinions about high-stakes tests (Thompson, 2001). High expectations are imperative if students are to achieve at high levels (Gratz, 2000), but the leap from high standards to rigorous accountability through high-stakes testing has not been justified by an increase in student achievement (Amrein \& Berliner, 2002). Students do not achieve on tests simply because they are told to. Some work more diligently in light of higher expectations, but others stop working at all in order to justify potential failure (Covington, 1992; Gratz, 2000). The Department of Education already projects that $14 \%$ of all high school students will leave school before attaining a diploma (Fair Test \& Massachusetts CARE, 2000), and highstakes exams will exacerbate the problem because many students will not be coerced into working more diligently 
without a better reason than standardized tests (Neill, 2003).

People are often motivated by a desire to protect their feelings of self-worth, and in some instances, failure on a standardized test due to lack of effort is more acceptable than failure in spite of honest effort (Covington, 1992). Recent research also supports the notion that external measures do not provide a complete picture of a student's motivation. As Mercado (1998) asserts, standardized test scores say more about how we "organize environments for learning than about the abilities and capabilities of students in marginalized communities" (p. 69).

This is not to say that measuring student learning is not an important or reasonable goal. Teachers can use assessments as information to improve their practice and to help students see where more work is necessary (Dweck, 2000). In order to sort out this issue, stakeholders must identify whether the real goal is to measure achievement or to ensure authentic learning. This question drives many education researchers who explore ways that motivation is generated from within although affected by external factors as is discussed in the next section.

Internally Generated Motivation

This section will discuss the belief that posits that motivation is internally generated. Each element that generates intrinsic motivation is influenced by contextual 
factors. When students are curious about the task at hand and feel confident in their ability to meet the challenges it presents, they are more likely to be motivated (Strong, Silver, \& Robinson, 1995). This section will explore issues such as the importance of valuing personal literacies, teacher/student relationships, flow theory, autonomy vs. control, and learning orientations in order to make transparent the effects of context on intrinsic motivation. Personal Literacies

Smith and wilhelm (2002) studied 40 boys in grades six through twelve and found that "various groups of young people employ powerful literacy practices outside school that go unrecognized, untapped, or unvalued in school" ( $p$. 19). For example, the researchers asked their participants to record each literacy experience in a journal. When Wilhelm ran into some of the boys at a movie theater, he overheard them discussing the movie reviews they had researched on the Internet. The boys engaged in a lively discussion about which movie to see based on the comments of critics, but they did not include that literacy experience in their journals. When questioned about their decision, they told the researchers that they did not think anyone was interested in "that kind" of reading.

When students' literacy practices are unvalued or unacknowledged, school sends the message to these learners that what they bring to the learning experience is not desirable (Smith \& Wilhelm, 2002). If students feel that 
they have nothing to contribute to their school or classroom community, their intrinsic motivation suffers because they do not see a reason to engage. They save their energy for the pursuit of their interests outside of school. "Many come to see themselves as competent individuals outside of school in ways that are not well-aligned with school. As educators, our task is to help students recognize this competence and see how it can be transferred to academic contexts" (Hinchman, et al, 2003/2004). Because society in general and schools in particular tend to equate accomplishment with a person's value, some students disengage because they do not see a connection between their abilities and the opportunities for accomplishments provided by school (Covington, 1992). Thus, they choose not to take the risk of failing at a school task or assignment. When students feel that their teachers are committed to their personal and cognitive development, they are more motivated to take an active role in their learning (McCombs, 2002). Relationships

Some research suggests that teachers play a vital role in helping their students find reasons to engage (Dweck, 2000; McCombs, 2002), and that the physical classroom, an abundance of technology, or other material goods alone do not affect the amount of effort that students choose to exert (Daniels \& Arapostathis, in press). When students are included in class or school decision-making, they are more inherently motivated (McCombs, 2002). They like it when 
teachers want to know what they think and feel. Teachers can work with students to teach them how to control their negative thinking (McCombs, 2002) which increases their feelings of self-worth as well as allowing them to feel more autonomous (Deci, Vallerand, Pelletier, \& Ryan, 1991). When the students feel that they are in control of the decisions they make, they are more likely to engage in school (Deci, Koestner, \& Ryan, 2001).

When teachers give explicit instructions and specific feedback on student performance (Stipek, 1998), act as resource persons who support student learning (Brophy, 1998), and emphasize interpersonal processes inherent in learning (Johnson \& Johnson, 1985), they create contexts that foster intrinsic motivation. The relationships that students develop with trusted adults increase the likelihood that they will work more diligently in school. "When students are asked what is right about schools, they most frequently mention high quality human relationships in which people care, listen, are honest and open, understand and respect others" (McCombs, 2002, p. 10). Flow

One arm of the motivation research focuses on the theory of flow. Csikszentmihalyi (1990) has spent decades researching what motivates individuals and defining the elements of a motivating experience. Whether learning a new skill, participating in an enjoyable activity, or facing a complex challenge, people often focus their consciousness as 
they immerse themselves in the task at hand to the extent that they lose awareness of any extraneous stimuli. That level of engagement is called flow.

According to Csikszentmihalyi (1996), the conditions necessary to enter flow are 1) having clear goals for each step of the process, 2) having immediate feedback as to the consequences of one's actions, 3) balancing between the challenge at hand and the skills a person possesses to face it, 4) having no worry of failure because the action is autotelic-an end in itself, and 5) losing awareness of time or outside distractions because all attention is focused on the task at hand (pp. 111-113). Csikszentmihalyi's research is valuable for educators because the conditions necessary to enter flow are echoed in the other research on motivation which suggests that people are primarily motivated when they have clear goals, specific feedback, and a sense of competency and autonomy (Deci, 1995; Dweck 1991; Stipek, 1998). What appears to keep people motivated is "the quality of the experience (that is an) almost automatic, effortless, yet highly focused state of consciousness" (Csikszentmihalyi, 1990, p. 110).

Although not all students arrive at school with the same level of intrinsic motivation or with the same readiness to deal with challenge, they can learn strategies that will help them enter flow and/or become more motivated to engage in learning experiences. Perry (1999) found that high school writers entered flow when purposely using 
specific strategies such as taking control of emotions, redirecting attention to more interesting aspects of the topic, and setting up daily work times and goals all of which are behaviors that contribute to students' feelings of autonomy. Although these strategies may not be innate for students, they can be taught explicitly so that students internalize them. Although students might not initially see the value in studying concepts that "were discovered recently in our evolution" (Csikszentmihalyi, 1996, p. 125) such as geometry proofs or essay writing, teachers can create contexts that help their students find reasons to engage. When students learn that they can control their focus and their mental energy, they feel more autonomous, which positively influences their motivation (Deci, 1991; Dweck, 1985).

Autonomy vs. Control

When autonomous individuals engage in activities that matter to them, they do not need external motivators to work toward success. Csikszentmihalyi (1996) found that creative people are driven by internally focused energy that comes from personal goals and ambitions as opposed to external dictates. When educators teach students that they do have control over their choices, thoughts, and actions, they support their students' autonomy which fosters intrinsic motivation because the choice to engage comes from within as opposed to being externally imposed (Deci, Vallerand, Pelletier, \& Ryan, 1991). When students engage because they 
see value in the learning experience, that intrinsic motivation leads to increased engagement (Bandura, 1991). These feelings of autonomy are not often supported through traditional school settings that tend to value achievement over effort as is evidenced by awards ceremonies, classroom practices, and other events that value competition and limit the number of students who can be recognized for achievement. Instead of defining success as achieving more than others, teachers and administrators might consider defining success as the improvement against personal accomplishments or progress toward personal goals. When a student learns to measure success in those terms, then his/her success is not seen as "incompatible with that of others" (Dweck, 1985, p. 294). When schools emphasize that all students should achieve at their highest levels instead of trying to beat each other, control shifts from the hands of educators to the hearts of students (Covington, 1992). If success is not viewed as a finite entity that only achievable by some, more students will be likely to engage in learning experiences (US Department of Education, 1992) because this conception of achievement encourages students to strive for excellence as opposed to equivalency with their peers (Covington, 1992). Learning vs. Performance Orientations Students' feelings of autonomy often affect their attitudes about their ability to learn. Elementary schools tend to focus on the learning process instead of on the 
attainment of specific outcomes. The former focus fosters, in many children, an attitude that ability is a dynamic process that can be influenced by effort and engagement (Dweck, 1991). Once students begin middle school, however, the consequences for failing become more severe in the form of negative grades, retention, and disciplinary action (Alspaugh, 1998). Even students who were successful in elementary school struggle when they reach the higher grades because the emphasis shifts from learning to measurable achievement (Dweck, 1991). For students who already believe that ability is a fixed entity over which they have no control, this shift threatens their sense of self-worth and can lead to disengagement and a decline in academic achievement (Covington, 1992; Dweck, 1991).

If students feel that they cannot control their abilities, they are more inclined to give up when faced with a difficult task. They do not see the purpose in attempting a challenge if they do not feel they have the necessary skills to experience success (Csikszentmihalyi, 1990). It is more attractive to justify failure because of a lack of effort than to risk failure in spite of trying one's best (Collins, 1996; Covington, 1992). When Dweck (1991) tracked the academic performance of students entering middle school, she found that those students who believed that they had control over their abilities remained or became high achievers. She hypothesizes that because those students had not tied their self-worth to what they believed is a static 
entity, they were more willing to take risks and to engage in school learning experiences. Her work supports Csikszentmihalyi's (1990) flow theory in that he found that people who were most successful believed in their power to control the outcomes of their endeavors.

\section{Implications for Research}

The bodies of literature on flow theory and educational psychology inform each other and form the basis of a discourse which holds that student motivation is internally generated but influenced by the context of the learning experience.

By including student voices in the conversation about motivation and achievement, this study attempts to bridge the gap between theory and practice in order to help teachers create environments that support the engagement, learning, and achievement of all students.

What we Still Need to know

Much of the motivation research has been conducted in the psychological arena. Educators' practical daily concerns mean that articles and research must cross academic boundaries, make theory accessible, and provide real, workable solutions to teachers' challenges. Existing theories and beliefs must work toward giving teachers practical realities that are steeped in theory but are ready for classroom application.

Csikszentmihalyi's flow theory (1990) describes how people find happiness and satisfaction at work and at play. 
The practical applications for classroom teachers are implied but need to be made explicit. Csikszentmihalyi, et al (1993) also studied why talented teenagers choose to develop or ignore their gifts, which offers insights for teachers of adolescents. Because he focused on students with special talents or gifts, however, we do not know whether his findings are applicable to average or struggling learners.

When classrooms are viewed as psychological instead of physical environments (Shernoff, et al, 1999), more avenues to fostering motivation are opened. In spite of the considerable work that has already been conducted, however, those same researchers cite the need to include the voices of the students in order to represent their perspectives on what conditions are most motivating (Storz \& Nestor, 2003; Zhu, 2001). Cushman (2003) talked with 40 high school students whose insights enlighten both novice and veteran teachers. Talking with middle school students in the same vein will create a more complete picture. Shernoff, et al (1999) state that "a major problem with studies of motivation has been that they have tended to isolate measures of motivation from the contexts in which motivational processes typically occur" (p. 5). Storz and Nestor (2003) assert that "the voices of urban middle school students seldom have been heard" (p. 11), but when asked the students "sent a clear message to middle school professionals" (p. 19). The intent of this study is to 
contribute to the existing literature by allowing middle school students themselves to articulate how they interact with and construct meaning from their environments in order to understand how their internal motivation is affected.

Erickson (1984, 1987) studied resistance among school children, and he believes that students often resist or disrupt because they do not want to be defined by the school or their teachers. A negative reputation forged of individual volition provides a better self-image than a positive one that is shaped by outside forces. The implications of this theory for classroom teachers have not yet been made explicit but appear to connect to Csikszentmihalyi's work on flow theory. Schools play a role in constructing reality, and learning is a social experience (Finders, 1997). Because of these findings, this study represents the voices of students as they make their transitions to middle school in order to produce deeper insights into their needs. This will allow teachers to create more motivating learning environments which, in turn, will lead to greater student effort and academic achievement. 
Chapter Three

Methodology

The purpose of this qualitative study was to explore whether a connection exists between the school contexts and the academic and social choices of students in their first year of middle school. In order to identify such a connection, the following research questions were investigated:

1. What elements are in the context of middle school that affect earned achievement and the desire to engage in school for adolescents?

2. Why do these contexts affect some adolescents and not others?

3. What roles do teachers and schools play in the creation of these contexts?

In order to explore the research questions and meet the purposes described in this study, this research project was a collective case study (Stake, 1995). I gathered data by surveying, interviewing, and observing students during the beginning months of their middle school experience.

Through an initial information survey, I learned what young adolescents at two middle schools in a small, coastal town in the southwestern United states thought and felt about their lived experiences as students. This town provided a home primarily to Latinos and Caucasians from a wide range of socioeconomic groups. After receiving the initial surveys, I conducted in-depth interviews with nine 
students who indicated interest in the project. In this way I was able to verify findings from the survey data. Since both surveys and interviews were self-reports, I also spent four days on the middle school campuses in order to better understand the contexts in which the students told their stories. Because sociocultural theory provided a conceptual framework for this study, this methodology was based upon the primary tenets of the theory. As shown in Table 1, methodological decisions were supported by theoretical assumptions.

By eliciting stories through interviews and then analyzing those narratives, I explored the meaning that students created from the stories they told (Bruner, 2002) and attempted to identify the relationships among seemingly independent events in order to understand how they were connected into a meaningful whole (Polkinghorne, 1988). By interviewing and observing students, I learned about what they said exists in the contexts of their middle school that contributes to their engagement or lack thereof.

The surveys and in-depth interviews provided a forum for the participants to tell stories about their lived experiences as middle school students. Observations provided additional information about the culture in which the stories are lived. The data illuminated cultural models and themes that will allow teachers to understand how students construct meaning from their middle school experiences (Gee \& Green, 1998). 
Table 1. Connection between theory and method

Theoretical assumption

Context is defined by the

language used, the artifacts

employed, and the actions taken

in each situation (Gee, 1999).

People use language, among other

tools, to construct meaning from

their experiences.

Language is always situated in

a larger context (Bakhtin, 1986).

Through feedback from different

groups with whom they are

associated, adolescents learn

which behaviors are appropriate

and desirable (Cole, 1996).
Methodology

During the interviews,

I looked for themes and

cultural models that

appeared in the stories

as they described

relationships and

experiences.

I analyzed the language

that students used in

order to see how it

affected their

relationships.

By listening to the

participants' stories

and observing them at

school, I analyzed how

the feedback they

received influenced their

decisions. 
and achievement. Although the media are filled with negative stories about adolescents and their school achievement, some research suggests a different narrative. Students can be and want to be successful if provided with a context that values what they bring to school and gives them challenging but relevant learning experiences (Oldfather, 1994; Smith \& Wilhelm, 2002; Storz \& Nestor, 2003). For example, teachers who are aware of how the artifacts they employ contribute to the quality of students' learning experiences create contexts in which students' literacy practices can be valued and recognized (Smith \& Wilhelm, 2002). By using discourse analysis (Gee, 1999; Gee \& Green, 1998) to examine the stories of students, this study explored existing researchers' conclusions. In Smith and Wilhelm's research for example, they found that students did not think that most teachers were interested in the abilities that they brought from home. For example, when studying movie reviews on the Internet in order to decide which movie to see, the boys commented to the researchers that teachers were not interested in "that kind" of reading. They were motivated to achieve in classes where the teachers appeared truly interested in their abilities and interests.

Sample Selection

Because I wanted to learn about the lived experiences of average students during their first months as middle school students, I identified the participants through a stratified purposeful sample (Creswell, 1998). Data 
collection occurred at two middle schools in a small, coastal town in the southwestern United States. One middle school (Willow Glen Middle School) educated sixth, seventh, and eighth graders, while the other (Highlands Middle School) served only seventh and eighth graders. Working with both schools provided a more complete picture by allowing additional exploration into whether age is a variable in the meaning that students construct from their environments.

Both middle schools serve children from extremely wealthy and extremely poor families. Caucasians and Latinos compose the dominant ethnic groups. Using the rosters of the students in their first year of middle school, I identified the gender and ethnic composition of each group of students. One hundred twenty five participants from each school were randomly selected through the first period physical education classes. A letter was sent that described the purpose of the study, the anticipated time commitment, and the investigator's contact information to those 250 students and their parents. In the letter, I asked the parents to contact me if they had further questions and to return the parental permission and student assent to participate forms as quickly as possible. Upon receiving the permission and assent forms, I sent the initial information surveys (Appendix C) to the students who agreed to participate. As Table 2 shows, the responses from each participating middle school were similar regardless of the respondent's grade level. By numerically coding the surveys, I was able to 
assure the parents that the students' responses remained anonymous. I am the only person who had, and continues to have, access to the students' real names. Table 2. Responses from Willow Glen and Highlands Middle Schools

Breakdown of responses Willow Glen $\left(6^{\text {th }}\right)$ Highlands $\left(7^{\text {th }}\right)$

Total number of $6^{\text {th }}$ or $7^{\text {th }}$ graders 258

Number of surveys sent $\quad 125$

Number of responses

Upon receipt of the completed surveys, I stratified the responses according to the demographics of each middle school using a previously assigned numeric code. Table 3 illustrates the demographics of the respondents. I randomly selected five participants from each school, again representing a range of ethnicities and genders. Based on the numeric code, I identified those students. The principal at each middle school contacted the parents to ask if they would allow their children to participate in an in-depth interview. Once the parents agreed, the students themselves were asked to participate in the interviews. The principals and I explained that this was an opportunity to explain what middle school has been like for them, and we emphasized that their responses would be kept confidential and would in no 
way affect their grades, social standing, or extracurricular activities. Nine of the ten students agreed to participate. Finally I spent four days at the middle schools unobtrusively observing the study participants as they interacted with their teachers, peers, and administrators. This final portion of data collection was important in order to provide information about the context in which the students' stories occurred. Observing how the students interacted in the context of middle school deepened my understanding of the stories that they tell (Cole, 1996; Wertsch, 1991).

Table 3. Demographics of respondents

Demographic information Willow Glen $\left(6^{\mathrm{tn}}\right)$ Highlands $\left(7^{\mathrm{th}}\right)$

$\begin{array}{lcc}\text { Number of Caucasians } & 16 & 12 \\ \text { Number of non-Caucasians } & 5 & 7 \\ \text { Number of female responses } & 10 & 11 \\ \text { Number of male responses } & 11 & 8\end{array}$

Many studies have been conducted that explore the experiences of specific gender or ethnic groups (e. g. DeBlase, 2003; Smith \& Wilhelm, 2003), and that work has contributed to educators' understanding of each group's unique needs. I was interested in adding to the work that has already been done and in identifying realistic approaches teachers can take when faced with a typical class that consists of many different ethnicities, genders, and 
academic abilities. Therefore, focusing on one particular race, gender, or academic ability would not have provided data useful in addressing the research questions for this study because such isolation is not present in the every day lived experiences of most middle school students.

\section{Data Collection}

During the summer of 2003, I contacted the principals of both middle schools in the school district, explained my proposed study, and obtained permission to conduct research in their schools. Although district policy did not require district level permission to be granted, I also contacted the assistant superintendent and received his verbal permission. Both principals wrote letters of support that were attached to the application for approval from the Institutional Review Board (IRB). Once my proposal was approved by my dissertation committee and the university IRB committee, I contacted the schools again in order to obtain the randomized list of incoming students for the mailing of the surveys. Because of the need to protect the students' privacy, I gave stamped envelopes containing the parent permission and student assent to participate forms to the principals, and they affixed mailing labels and sent the letters. Because of this process, I never had access to the students' home addresses or phone numbers. Instrumentation

I used two data collection instruments-an initial information survey (Appendix C) and an interview protocol 
(Appendix D). Both instruments were used in a previous study (Daniels \& Arapostathis, in press) and produced information that was useful in analyzing the students' experiences. On the information survey, I asked questions about the student's interests, experiences in, and attitude toward school. For the interviews, I used an interview guide with specific questions to be asked, but I also asked follow-up questions in order to elicit as complete stories as possible. Although I asked each student the same questions in the same order, the follow-up questions varied from student to student as those queries were dependent upon comments made during each individual interview. This was in keeping with the approaches of other qualitative methodologists' approaches (e. g. Stake, 1995; Taylor \& Bogdan, 1998). In order to analyze the participants' stories thoroughly, I tape recorded the interviews for transcription. Parents gave permission for this when they signed the parental permission form.

Interviews

In an adaptation of Stake's (1995) work on interviewing in qualitative research, I conducted one in-depth interview of each of the nine students who were chosen from the original survey participants.

I asked students to reconstruct their school experiences (both positive and negative) so that I could explore the meaning they constructed from their lived experiences as middle school students (Taylor and Bogdan, 
1998). It was important to keep my questions general in order to avoid imposing my own meaning-construction on that of the students (Stake, 2000). Because sociocultural theory underpins this study, I asked students about their interactions with others and their thoughts and feelings about middle school in order to identify connections across time and experience (Gee \& Green, 1998).

A final interaction with the participants occurred after I analyzed the survey, interview, and observation data. In order to ensure that the meaning I created was an appropriate representation of the students' meaningconstruction, I wrote a profile of each interview participant. See Appendix B for a sample of the profile. I sent the profile to the student and asked for his/her feedback on my interpretations. Although I retained the final say on what information I used, this step allowed me to verify the accuracy of my analyses (Stake, 1995). All of the students stated that I had understood what they were trying to say.

Observations

Qualitative researchers have long suggested using multiple data sources in order to obtain enough information to deepen understanding of the issues to be studied (Stake, 1995; Taylor \& Bogdan, 1998). Combining interviews with observations allowed me to understand the context of the students' responses (Taylor \& Bogdan, 1998). Additionally, Shernoff, et al (1999) claimed that "a major problem with 
studies of motivation has been that they have tended to isolate measures of motivation from the contexts in which motivational processes typically occur" (p. 5). The intent of this study was to address the problem identified by Shernoff and his colleagues. I wanted to learn how cultural artifacts and interactions with others contribute to students' decisions to engage or not engage in school learning experiences. Observing the participants in the context of their middle schools supplemented the picture created by the students.

After completing the interviews, I made arrangements with the principals at the middle schools to shadow four students for one day each. Because I supervised student teachers at one of the schools, my presence was expected and unremarkable. At both middle schools, I remained as unobtrusive as possible in order to minimize the effect of my presence on the students' behavior.

Before beginning the shadow days, I talked with the teachers so that they knew to expect my presence. I made it clear that my purpose was not to evaluate the teachers but to observe how students interacted in various classrooms and that the write up of the findings would not include any real names. Because I had been trained as a Beginning Teacher Support and Assessment (BTSA) support provider, I understood how to take observation notes that are descriptive and not evaluative. I recorded events as they occurred and comments 
as they were spoken without including my own thoughts, judgments, and opinions.

During the observations, I understood that taking detailed field notes and allowing time for analysis and reflection was imperative to my own construction of meaning (Taylor \& Bodgdan, 1998). While walking around the schools and sitting in classes and at lunches, I listed my observations on a clipboard that I carried at all times. In accordance with my BTSA training, I wrote specific quotes that I heard and recorded specific interactions that I observed. By recording everything that I saw and heard in a descriptive, not evaluative, manner, I attempted to ensure that my field notes contained information that was useful as I reconstructed the context during data analysis. I used the observations as tools to document the organization of verbal and nonverbal behavior (Erickson, 1992) in order to explore how the context directs the meaning that the participants construct. These observations helped me to understand the impact of contextual artifacts and human interactions on the students' experiences and choices (Wertsch, 1991).

\section{Data Analysis}

Because the purpose of this study was to represent the students' thoughts and perspectives through their own voices, I focused on identifying the meaning they made about their lived experiences. In order to ensure that my data analysis matched the research purposes, I used both qualitative and quantitative methods when analyzing the 
data. The analysis explored the cultural models and situated meanings that emerged from participants' interactions with others in the context of their middle schools (Gee \& Green, 1998). Understanding how semiotic artifacts influenced the cultural models in use and the situated meanings that are employed reflected the influence of sociocultural theory on this study.

Qualitative Analysis

Analysis is a means of taking an experience apart and finding meaning in each part (Polkinghorne, 1988; Stake, 1995). With this in mind, I read the surveys, the in-depth interview transcriptions, and the field observation notes looking for emerging themes and cultural models that illuminated the students' experiences and provided insights into how they constructed the meaning that they did. I utilized Gee's (1999) approach to discourse analysis because he posits that researchers can use all elements of a situation-activity, materials, and interactions-to understand how identity and meaning are constructed.

The students' stories were collected because stories are tools with which we make sense of our experiences (Clandinin \& Connelly, 2000). The stories were analyzed because I wanted to explore how students describe relationships and experiences and what those descriptions said about the meaning that they constructed and the identities they enacted (Gee, 1999). Context is created, at least in part, by language, and language is how cultural 
models and situated meanings are made explicit. (Gee \& Green, 1998). To guide my data analysis, I used both Polkinghorne's (1988) premise that "truth is a creation within speech that presents itself as adequate" (p. 30), and Shernoff et al's (1999) assertion that participants' words can be taken as the truth as they know it.

Strauss and Corbin (1998), Charmaz (2000), and Creswell (1998) all described the process of coding interview transcriptions and field notes according to emerging themes or categories. These themes illustrated the cultural models that the participants used for guidance when assimilating the information and experiences present in their new context, which is middle school. My intent was to represent the students' voices in such a way that teachers and administrators would listen to whatever the students had to say.

As I noticed recurring ideas in the participants' words, I noted them as emerging codes or categories (Charmaz, 2000). Whenever possible, I named the categories using the participants' own phrasing (in vivo coding) . Creswell (1998) identified this process in his discussion of procedures designed to ensure rigorous qualitative analysis. By using the participants' words, I hoped to ensure that their voices were accurately and honestly represented. My thinking was influenced by Shernoff et al, (1999) who claimed that we take a "philosophical leap of faith" when we study student perceptions and thus it "is not necessary to 
acknowledge the existence or accuracy of the event anywhere else but in consciousness" (p. 17).

Based on personal experiences of eight years of teaching disengaged learners, professional readings throughout this doctoral program, and a similar (but smaller) study (Daniels \& Arapostathis, in press), I believed that emerging themes might also reflect the themes identified throughout Csikszentmihalyi's work on flow (1990; 1996). By combining Gee's (1999) suggestions for discourse analysis with Csikszentmihalyi's (1990) findings from his flow studies, I used the data analysis to construct meaning from the participants' stories and actions. Although I had initial thoughts as to what students might say, I was wary of putting words into their mouths. As such, I continually asked for clarification during the in-depth interviews. When a student answered a question, I often repeated what he/she had told me in order to check my understanding of his/her perspective. I also rephrased many questions in order to elicit as complete answers as possible. Sending summary profiles to each participant also helped to ensure that I did not impose my own preconceived notions into the students' stories and experiences.

In order to illustrate what the data analysis looked like, the following section offers and example of how I conducted the initial survey analysis. 
Specific Example of Analysis

As surveys were returned, I read through each of the comments written by students. One of the questions asked, "Is doing well in school important to you? Why or why not?" Following are three sample responses:

- It is important that I do well in school so that I can get my degree in college and become an architect.

- Yes, because since I have an older brother and sister I already know you need to get great grades to get into college.

- It's important to me because whenever I do good in school it makes me feel better about myself.

When I read the first response, I noticed the words "college" and "architect". Both of those words suggest an interest in or concern with the future. Thus I created a category titled "future/college" and put that statement into that category. The second statement also suggested an expectation of college being part of the student's future so I put that statement into the "future/college" category as well. When I read the third statement, however, I noticed a new theme emerging. "Feeling better about oneself" became a second category. As I worked with the data in that particular category, I made connections to existing research that suggested that self-concept in middle school is important in terms of motivation. Thus the reading done to prepare for this study contributed to a deeper understanding of the students' stories. 
As I moved between the structure of the students' language and the situated meanings inherent within (Gee, 1999), I began to understand the meaning that they constructed about their worlds. By exploring the key words and phrases in the students' responses, I began to understand the dominant influences in their lives. Quantitative Analysis

Although this study focused on eliciting students' narratives in order to represent their voices in the debate about student motivation and achievement, I also conducted a quantitative analysis of the categories that emerged from the surveys and the interviews. I quantified the number of responses in each category that emerged from all of the surveys and interviews. For example, I entered the number that each student circled on each of the first nine survey questions into Microsoft Excel. By directing the computer program to calculate the average score for each question, I determined whether there was a difference in the way sixth and seventh graders experienced the new context of middle school. I also listed each contextual factor that was mentioned in either the surveys or interviews. For example, friends, multiple class periods, homework, and food all emerged as parts of the middle school context that affected students' engagement and motivation. By calculating the number of students who referred to these elements in either their survey or their interview, I determined the percentage of responses (both survey and interview) that identified 
specific contextual factors or teaching practices in order to illustrate the students' perspectives numerically as well as in narrative.

Adding this statistical information enhanced my understanding of the themes and categories that emerged from the qualitative analysis and was more effective in informing the high-stakes assessment discourse described in Chapter Two. As previously discussed, this discourse places a heavy emphasis on test scores and other statistics when determining teacher effectiveness and student achievement (www.ed.gov/legislation/ESEA02). By using the language of the high-stakes discourse, this study hoped to position the findings to be heard by those who have an impact on what teachers are mandated to do for their students.

$$
\text { Validity }
$$

I understand that my perspectives and preconceptions may have played a role in my data analysis. A valid qualitative study would not seek to eliminate this reality; rather it would seek to understand the interaction between the researcher's values and his/her conclusions (Maxwell, 1996). In order to ensure that my conclusions were valid, I searched for discrepant evidence, sought participant feedback, used triangulation of data sources, and provided rich, thick description when writing up my findings (Creswell, 1998; Maxwel1, 1996).

Because of my personal experiences with, and reading the literature about, disengaged learners, I held beliefs 
about the reasons they choose to engage or disengage. It was my sense that young adolescents who disengaged from school learning experiences did so because they did not feel a connection to their teachers or other adults and did not see the relevance in the school tasks they were asked to complete (Daniels \& Arapostathis, in press). With experiences as both a middle school teacher and a ninth grade teacher in an alternative school, I have seen that some students will do whatever is asked of them in order to please the teacher. Others will not work at all unless their teacher helps them to see a connection between the school assignment and their own lives.

The relationships teachers build with students are also critical. I have had students who will purposely and repeatedly disrupt my class if they do not feel that I have connected with them on a personal level. Conversely, I have had students who will not work in any class but mine because they believe that I understand who they are and what they need.

In order to ensure that my own beliefs did not unduly influence the conclusions, I searched for discrepant data. The participants' narratives provided the data for my analysis, and I examined my field notes and interview transcriptions carefully to find and identify stories, comments, or reactions that did not support the emerging categories. In my write-up, I identified these negative cases as possible alternative explanations to the 
conclusions of this study. Stake (1995) asserted that "good case study is patient, reflective, and willing to see another view" (p. 12), and I kept this admonition in mind throughout this study. I also asked a colleague to read the interview transcripts and summary profiles that I wrote for each interview participant in order to search for evidence of any preconceived notions that might have been imposed onto the data analysis. She offered suggestions as to the meaning she made of the students' stories that were closely aligned with the analyses presented in the summaries. An example of one summary profile can be found in Appendix B. seeking participant feedback and triangulating data sources were two additional analysis techniques in which I also engaged in order to ensure the validity of my conclusions. Because the primary focus was providing a forum in which the students' voices could be heard, I sent summary profiles to each interview participant and asked them if I had represented their stories accurately. By engaging in these post-interview interactions with the participants about the narratives they shared, I hoped to create a picture of the students that was accurate, honest, and compelling for their teachers.

This led to a final strategy to ensure validity in the data analysis. When analyzing the students' stories, I kept the emerging categories linked to the data that generated the categories so as to keep the context within which they were derived intact (Maxwell, 1996). When telling the 
students' stories, I used thick, rich description so that readers of my work are able to understand what elements in the context of middle school contributed to their choices to engage in or disengage from learning experiences. Instead of looking for easily explained answers, I used the students' narratives as the vehicle by which I explored the depth and complexity of their lived experiences (Marshall \& Rossman, 1989). If I am faced with criticisms about my analysis, I will make my data available to the critics so that they can demonstrate how a different meaning could have been constructed (Gee, 1999). As Gee (1999) noted, analysis should be based on the details that are "deemed relevant" to the argument I am attempting to make. If a reader does not agree with my argument, I must be able to support it with the reasons behind my analysis.

\section{Implications}

With an awareness of the multiple layers of narrative at work for the students in this study (Clandinin \& Connelly, 2000), I hoped to represent multiple voices that do not often have a forum for expression. In this way, I met one of the goals of qualitative research which was to offer those who have been silenced an opportunity to speak (Lincoln, 1995; Taylor \& Bogdan, 1998).

Mercado (1998) worked with middle school students in New York City and engaged them as co-researchers. She wrote that the young adolescents were capable of participating fully in the research process and that the thinking and 
analyzing required in such activities led them to new understandings of possible selves. This current study revealed that young adolescents are also capable of discussing the factors that both encourage and inhibit their motivation to achieve in school. Since it appears that external factors do influence internal motivation, this study might provide teachers with a way to re-conceptualize adolescents as learners. 


\section{Chapter Four \\ Findings}

The purpose of this study was to explore whether or not a connection existed between students' school contexts and their academic and social choices by listening to the voices of first year middle school students. This study focused on three research questions that explore the possible influences on student motivation and achievement during the transition from elementary to middle school. The questions are the following:

1) What elements are in the contexts of middle school that affect earned achievement and the desire to engage in school for adolescents?

2) Why do these contexts affect some adolescents and not others?

3) What roles do teachers and schools play in the creation of these contexts?

The questions constructed a frame for exploration and analysis of the students' stories. This study provided a forum for young adolescents' voices, and their responses to each of the research questions offered qualitative data based on what the students had to say. After analyzing the data from surveys and one-on-one interviews, I identified the themes or patterns that emerged from the students' stories. In this chapter, I place those themes within the context of the appropriate research question in order to 
examine the ways in which students speak about their motivation.

Gee (1999) said that situated identities are the identities or social positions that people enact and recognize in various settings. These identities are developed according to what people expect from and understand about appropriate ways of being in any given situation. It seemed as if the middle school students in this study worked to construct their identities both as students and as unique individuals. Because this is a process that early adolescents have only recently begun to consciously undertake, their home and school identities are often closely connected but begin to diverge as the students enter young adolescence. This divergence appears to explain, in part, why the context of middle school has an impact on students' motivation and achievement.

The mind is a pattern seeker and the meaning of those patterns derives from the social and cultural contexts in which the patterns exist (Gee, 1999). As such, analysis of the student-participants' stories focused on identifying patterns within their words in order to understand the sense they have made of their experiences. This research articulates what the students had to say about their middle school experiences in order to explore how the patterns that exist within their responses and stories lead to a deeper understanding of the research questions framing this study. 
The reader will meet nine sixth and seventh graders who spoke to me at length about their middle school experiences. Comments written by the other 32 survey respondents will also be used to support or echo the stories told during the in-depth interviews. Their stories and perspectives are insightful and informative for anyone seeking to create motivating learning environments that are responsive to young adolescents' demonstrated needs. Courtney, Jamie, Jorge, Silvia, and Mark are seventh graders at Highlands Middle School which serves only seventh and eighth graders. Kelly, Kid, Isabell, and TJ are sixth graders at Willow Glen Middle School which follows the more traditional middle school format of sixth, seventh, and eighth grades. Because their perspectives appeared to be consistent regardless of their grade level, this chapter is organized according to the patterns that arose from their stories, not by their school or grade. Table 4 summarizes the demographics of the interview participants. 
Table 4. Demographics of interview participants

\begin{tabular}{llll}
\hline Student name & Gender & Grade level & Ethnicity \\
\hline Isabell & Female & 6 & Latina \\
Kelly & Female & 6 & Caucasian \\
Kid & Male & 6 & Latino \\
TJ & Male & 6 & Chinese \\
Courtney & Female & 7 & Caucasian \\
Jamie & Female & 7 & Caucasian \\
Jorge & Male & 7 & Latino \\
Mark & Male & 7 & Caucasian \\
Silvia & Female & 7 & Latina \\
& & & \\
\hline
\end{tabular}

This study focused on representing how students are affected by the context of middle school. Based upon student responses to the survey (Appendix C), it appears that the students' perspectives are similar regardless of their grade level as is shown in Table 5. After reading each question, students circled a number between one and five to indicate their response. On each question, a response of "one" suggested the most negative attitude (i.e. not important, never, or nothing), and a response of "five" reflected the most positive response (i.e. very important, always, everything). The finding that students' responses were similar regardless of their grade level supported the organization of this chapter according to themes that appear to answer the research questions. 
Table 5. Average responses according to grade level

\begin{tabular}{lll}
\hline Survey question & $6^{\text {th }}$ & $7^{\text {th }}$
\end{tabular}

How important to you is doing homework?

4.4

4.4

How often do you participate in activities

that do not occur during the school day?

3.1

3.1

When you are in class, how well do you

concentrate on the lessons?

4.1

3.7

How often do you participate in discussions?

4.2

4.3

How often do you volunteer to read aloud?

3.9

4.0

How often do you talk to teachers outside

of class?

2.8

2.8

How do you feel about having several

teachers?

4.3

4.1

How much of what you do in your classes

are you interested in?

3.6

3.3

Describe your usual mood while you are at

school: alert-okay-tired OR

3.8

3.5

happy-okay-angry

4.2

4.4

Context of middle school

When students enter middle school, they are immediately faced with a much larger population of students than existed in their elementary school years, the demands of multiple teachers and class periods, and a wide range of elective and content area classes. Each of these contextual elements 
influences students' motivation and achievement in both positive and negative ways. After analyzing their stories, I have come to understand that the emerging themes often reflect the contexts in which the students function. Each element appears to either foster or inhibit the students' desires to engage in school and thus achieve or not achieve. The major themes from the participants' stories are discussed in-depth in this section, and Table 6 provides another perspective on how the context of middle school affects them. During data analysis, I listed each contextual factor that was mentioned in either the surveys or interviews. For example, friends, multiple class periods; homework, and food all emerged as parts of the middle school context that affected students' engagement and motivation. By counting how many students referred to these elements in either their survey or their interview, I determined the percentage of occurrences for specific contextual factors appeared in the students' stories in order to illustrate the students' perspectives numerically as well as in narrative. Some students identified certain contextual factors more than one time during their interview or on their survey which is why the percentages do not add up to $100 \%$. 
Table 6 . Contextual factors that affect middle school students Contextual factors Percent of responses

Interest in or relevance of classes $60 \%$

Stress caused by homework 548

Importance of friendships and other peers $48 \%$

Having multiple periods $34 \%$

Grades (as positive or negative) $28 \%$

Electives and P. E. $26 \%$

Teachers who positively influence motivation $24 \%$

Teachers who negatively influence motivation $22 \%$

Parents $22 \%$

Negative influence from other students $20 \%$ Food $20 \%$

Friends and other Students

In middle school there are many new people to meet- $6^{\text {th }}$ or $7^{\text {th }}$ graders from other elementary schools and older students. Existing friendships tend to either strengthen or fade away because of diverging interests, class schedules, and other pressures.

Each of the students in this study identified other students and/or friends as contributing to their comfort level in the new environment, and the students' experiences with their peers ranged from extremely positive to very negative. Many students discussed both new and long-term friendships as being a hallmark of their beginning months in 
middle school, but others felt that the need to protect their image, and the occasional bully, detracted from their experience.

Positive Experiences

Many of the survey comments mentioned that "meeting other kids,". "making new friends," "having tons of friends, even guy friends," "getting to be with my friends," and the fact that "there are more girls" make middle school fun. Sonia wrote that "the best part of middle school is that we get to hang out with friends and not being at home just watching TV," while being with friends made Amy "happy and alert." In an interview, Kid said that "I'm happy cuz I'm with all my friends." These comments support existing understandings that peer groups play a prominent role in students' attitudes, and the word "friends" appears repeatedly throughout the students' stories.

Having a best friend allowed Isabell to feel more comfortable at school because she had someone to eat lunch with and hang out with during the breaks. Kelly expressed a similar sentiment while talking about the comfort of being able to rely on her best friend, James, during the first weeks of middle school: "It helped cuz then I like didn't know anyone else so I'd just hang out with him." Trying to find someone to "hang out with" is a driving concern for most students.

old and new friendships helped smooth the transition to middle school because they helped the students feel 
connected with someone. Especially in the beginning, friends provided a support system as the $6^{\text {th }}$ and $7^{\text {th }}$ graders alike adjusted to larger campuses, multiple teachers, and passing periods. As Silvia explained, "Like in the first day, we were all looking for our classes, and we helped each other look for them. I never would have found them." This support system reduced the loneliness that many students felt. Jamie articulated her feelings by saying

If you don't have any friends, you're like going through school all alone. You just feel alone, like there's no one there that can help you. (With friends) you don't feel like you're the only person who's going through what you're going through in junior high and like when you have friends, you can talk about it and stuff like that and how you feel.

In addition to ameliorating loneliness, "talking about stuff" with friends makes it easier to deal with outside pressures. As TJ said, "My friends, they help me by supporting me all the way. If I have a little trouble, they just help me."

The students also knew how to find new people with whom they felt comfortable if their old friends were not available or no longer compatible. As Isabell said, "I sat with the girls who are in my classes who are nice and who don't talk that much." Mark agreed because he felt that he made friends by talking to the people who sat around him in his classes. The teachers facilitated this process by, as 
Mark said, having the students "introduce ourselves and then you learn names, who these people are." Meeting new friends during classes or breaks appears to be one of the highlights of middle school.

Beyond friendships, the students talked about their interactions with other peers and the mood that those interactions created on campus. Isabell has positive feelings about her middle school because she compares her experience to her cousin's at a different campus. In her opinion, Willow Glen does not have as many "psychos," who she defines as kids that scream at you when they don't know you. And she said that "we also don't have as many problems with gangs. Not that I know of." Both aspects make willow Glen a better place than her cousin's middle school. The simple fact that middle school represents "growing up" because they are with older students seems to engender positive feelings for many students. Courtney expressed the sentiments of many when she spoke about finally being at Highlands. As she explained,

In elementary school there were a bunch of kids who were younger than you. Like I walked to and from school, and you would see all these little kindergarteners walking behind you, and it made you feel really small. . . I always felt really big in $6^{\text {th }}$ grade (elementary school), like I was older than all the younger kids. But you're really not when you think about it because you go to the same school as a 5 year 
old. Here I like it better because then you say 'oh you're in jr. high, next step high school.' It makes you feel older.

Negative Experiences

Based on surveys and individual interviews, it appears that friends and other students are a major positive contextual influence for most of the students in the study. Yet there are negative experiences associated with the other students as well.

Charles, a survey respondent who also attends Willow Glen, wrote that the worst part is "the disrespect the kids show the school." TJ (another Willow Glen student) reported some experiences with bullies. Although he has developed coping mechanisms, and the bullies do not bother him too much, it irritates him to have to deal with them. TJ understands that "the bullies don't like it when I know more than them," but he does not seem to be scared of them. When they bother him, he walks away. "If they follow me, I'll probably tell them to stop and if they keep doing it, that's when I'll go to the extreme limits of my anger. I usually punch them." Although TJ does not like losing his temper, he is not willing to be pushed around. He has a very strong support system of friends which could be why the bullies do not seem to affect his positive feelings about the mood on Willow Glen's campus.

Because the middle schools are so much larger than most of the elementary schools, many of the survey respondents 
commented on the loss of friendships or individual attention. Judy said that "the worst part about middle school is that it's not a small, hunky-dory place. You often lose friendships." Zack wrote that the number of students in each class was the worst part of middle school, and Courtney talked about not participating in classes that were too big. Contact with the $8^{\text {th }}$ grade students is identified as something to be both desired and avoided. Matt contended that "the worst is the fact that you never see your $8^{\text {th }}$ grade friends, at least very rarely." Conversely, however, Jorge said that he likes being separated from the $8^{\text {th }}$ graders at lunch so that they do not make fun of him. Silvia commented that getting to know the other students was a challenge because "it's hard to memorize their names." Mark also addressed this issue and said that he likes teachers who help the students get to know each other during class time. While the survey respondents wrote generally about the loss of friendships or individuality, two of interview participants were much more specific about the difficulties they faced in terms of other students. At one elementary school, Jorge faced taunts and derision from students who told him to go back to Mexico and who made derogatory statements about his mom. As he explained, There were like six people that when I came from Mexico, they told me that they didn't like me, like Mexicans, and I didn't like that. I couldn't understand that. They said a bad word. They hate Mexicans and everything, and I felt 
bad, and I went home and told my mom, and I didn't want to be with them.

His mom moved him to a different elementary school where the students were nicer and more welcoming. "I got friends, and they didn't tell me nothing. I couldn't understand nothing. They just tell me what to do and everything, and they were helpful with me cuz I couldn't understand English." Not as many students taunt him in middle school, but he does try diligently to avoid the students who made his life so difficult at the first elementary school.

While other negative experiences are not as extreme, some students feel pressure to maintain images created in elementary school even if they do not want to. They want to impress their classmates. Courtney said that "I want to impress these people because they know me as I have been, but in this class, it's hard for me to be that way." She would prefer to be able to interact with other people on a one-on-one basis so that she would not have to worry as much about maintaining her image.

Classes

Classes themselves are another part of the context of middle school that influence student motivation and the desire to engage. Many participants said they experience classes that, as Sonia commented, allow them to "learn new and more hard things." Zack agrees that "school is fun because there is lots of important information." Many of the survey respondents thought that physical education classes 
are the best part about middle school, and Will liked having P.E. every day. The only negative statements about P.E. related to "dressing out" which appears to dampen some students' enjoyment.

Although P.E. was clearly a favorite for the survey respondents, the electives also drew rave reviews as James made clear by saying, "The best part is the exploratory wheel. The exploratory wheel is a class where you rotate through drama, art, broadcasting, and study skills." Jamie echoed James' sentiments when she said, "It's good to know, like we have a class we can choose. . you get to choose what you want to do. . . it lets you know that the teachers aren't just about themselves, and they want to let you have a fun time in school." Having a fun time in school-whether in electives or content area classes-matters a lot to the participants. Their specific likes and dislikes are further discussed throughout this chapter in terms of their impact on the students' desire to engage in class which, in turn, leads to academic achievement or failure.

Creativity

When middle school teachers value creativity and curiosity, students usually respond positively. They want to be able to "discover things new" (TJ). Being trusted to explore and have fun through "making new things" (TJ) encourages the students to engage more deeply in their classes. TJ notices that teachers who encourage creativity 
allow less than stellar students to shine as he described one example.

There's this one kid in our class that he usually has bad grades, and he did the legend of Sleepy Hollow. He got this 3D model of it. He got all these cool trees, and then he got the figure of the character. It was really cool how people can get bad grades but still do well on creative things.

Although not all students identified creativity specifically, many expressed a greater desire to work in classes where the teachers encourage "hands-on" learning (Charles). Mark "likes to share" his learning by discussing work with his classmates or doing presentations. Using counters in math or playing games to memorize dates in history made Silvia much more likely to participate in class. Silvia also questioned the rigidity of some rules that she felt inhibit creativity and learning. "Some people chew gum in class and get in trouble. I think it should be okay to chew gum in class because I learned chewing gum helps you concentrate more!"

\section{Relevance}

When the content of any given class matters to students or if they can see its relevance, they are more likely to engage in the class and thus achieve academically. "The human mind does not do well with general rules and principles that do not come out of and tie back to real contexts, situations, practices, and experiences" (Gee, 
1999, p. 48). This habit of mind is evident throughout the students' comments. Isabel1 understood how she will need math and language when she is older, but she thought of science as

less important than the rest of the things. . .because I don't really think I'm going to need science like the other things. Math, I'm going to need it a lot when I grow up. Also language you need to get a job, but in science I can't really think when I'm going to need it. Jamie felt the same way about social studies because "it depends if you want to be a historian when you're older, then, yeah, it's got a good purpose. But if you don't, I mean, why?" Or as TJ said, "If math weren't here today, they wouldn't be able to count how much money people had." When the students understood the reasons behind or use for what they were being asked to learn, they said they were more inclined to participate.

Another layer of relevance is the difference between classes that emphasize right and wrong answers as opposed to more complex thinking. If a class requires the student to "remember like the times and what the people's names were" (Silvia), students are not as interested in engaging. On the other hand, Courtney noticed that in some classes "there's no real perfect answer, then you just put whatever and can keep on going. But in English, it's just the answer. It's right or wrong like in math." If the class emphasized correct and incorrect answers, she wanted to know exactly 
what will be on the test so that she can focus her studying. These were the classes where she relied on extra credit because it was easier than the regular work. If there is no right and wrong answer, she liked to have a bit of structure (the topic is school) and then some freedom (you can write whatever you want about school). These were the classes where she participated and was happy to share her thoughts and opinions with her peers.

Student Needs

Classes that do not take into account individual student needs appear to inhibit engagement and motivation as well. Jorge still struggles with the English language, and thus he does not like the classes that do not provide language support. He said that "science is more hard than math. . . cuz I don't know that much English, and you have to read words. I like some words, but I don't know how to pronounce them. I got bad grades in science and on math, I got good grades." He said he would prefer to study science in Spanish before he is required to perform in English. Another expressed student need is to consider the balance of boys and girls in classes. Isabell wished that her classes had an even number of boys and girls because she would feel more comfortable about participating. She explained that "boys pretty much dominate the whole class. Even though they finish last, they still dominate the whole class. Girls like don't talk as much." 
Stress

Many of the interview participants talked about how the level of stress in their lives increased substantially when the entered middle school. Although they did not complain, they did appear to be overwhelmed as they learned how to balance additional demands on their time. The students identified several specific stressors that will be discussed in this sub-section.

Homework

Because school is not the only experience in students' lives that requires time and attention, the participants said they felt overwhelmed as they try to balance school, homework, and family commitments. All students, both survey respondents and interview participants, commented on the amount of homework they receive now that they are middle school students. Homework was by far the most prominent reason that students identified for not liking their new environment, and it appeared to detract greatly from their desire to engage, as well as their enjoyment of school.

Although students seemed to understand that doing homework is an inevitable and necessary part of middle school, they wished that it were more meaningful and deliberate. For example, Silvia thought that the homework should give the students "practice in what we're learning. . .because sometimes you forget." Jamie said,

Basically I hear from my friends that we have too much homework, and I definitely agree. It's way too much. 
It's way overwhelming. It's stressing kids out, and it's not gonna make them do better, forcing more work on them and thinking the more work we put, the more things we're gonna know. That's not true. I mean it seems right, but when you do it, it makes you want to breeze through and you want to get it over with. Having too much homework and feeling constantly under pressure does not encourage students to do or achieve more. Jamie said that it actually turns them off to school and makes them not care as much.

Kids can do better in school if you let them relax once in a while. Some of the kids, whether or not you have a lot of homework, would slack off anyway; but the kids that do want to try like me I guess that would definitely help.

Most of the participants echoed Jamie's perspective as each one talked about the amount of stress that they are under since entering middle school.

Other Commitments

When students feel that homework is taking away from their family time, they are less likely to complete it because of the limited number of hours in each day. Silvia explained, "Sometimes I have to turn in homework late because we have things going on at home, and I don't have enough time to do my homework." This also leads to resentment because, as Silvia said, "I think I go to school for a long time, and then I have more school work to do at 
home instead of spending time with my family." Isabell takes care of her little brother while her mom works and also goes to church frequently which limits the amount of time she has available for homework. Silvia and Isabell are illustrative of the tensions many students feel between the desire to achieve and the demands that family and other commitments place on them.

Extracurricular activities place another demand on the students' limited after school time. TJ plays two instruments and goes to Chinese school on the weekends, all of which require additional time and effort. He would like to quit one of his instruments, but

my mom says that piano is very, very important so she's making me practice about an hour a day. My other instrument, the clarinet, she also makes me practice that. - . If I have any free time, I usually go on the computer and search the web. That only happens once every month.

Finally, the physical realities of young adolescence make it less likely for some students to complete their homework. Jorge commented that "I just get sleepy, and I sleep and don't do my homework cuz I'm tired." TJ articulated the thoughts and feelings of many of his fellow students when he spoke about being "crowded." "It's like you're in the parking lot. Everyone's pushing against you. All that work I'm doing, it's pushing against you. It makes me feel very heavy headed." 


\section{Balancing Assignments}

Because the students in middle school have several teachers, they find that projects, tests, and homework are not always well-aligned. Having more than one teacher means that many assignments are due simultaneously which makes it difficult for some students to remember when assignments are due in each class. If the teachers have not coordinated with each other, students might have several tests and/or projects due within a span of a few days which increases their stress levels and makes achievement less likely. When there is no coordination among teachers, Jamie explained what can happen. "I have a lot of tests in the same week. I've had numerous amounts of homework every day pretty much." Kelly said that having papers due in more than one class makes it difficult to do well on either one. "If I want to start on one, and then I start on another, and I don't finish that one, then I get lost." Jamie agreed and says that sometimes students will study simply to remember what may be on the test and then forget the content soon after the test is taken.

Multiple Periods

A primary difference between elementary and middle school is the shift from self-contained classes to having different teachers for different class periods. Most students liked this change. As Jessica wrote on her survey, "The best part about middle school is the changing classes because you don't get tired of the teachers as quickly as in 
elementary school." Enzo, TJ, Scott, Faith, Emma, Zack, and Adam all made similar comments: "You meet new teachers," "I love how you have many teachers," "The best part is that I have a lot of teachers, and it goes faster." Having multiple class periods allows students to have more breaks and, for many, makes the day go faster.

Actually getting from class to class, however, detracts from the experience for some students if they get lost or need to talk to a teacher after one of their classes. Silvia said, "I kind of don't like it because you have to walk around the whole school and then you get tardy slips and everything." Other students will not ask for extra help because of the fear of being tardy to class. On her survey, Maria wrote that "what I don't like about middle school is that if you want to talk to a teacher after class, you can't because you have to be on time for the next class." Although aware of her need for extra help, Maria does not ask for it in order to comply with the school's tardy regulations. Amy wrote that she gets the teachers' names mixed up, and Kelsey agreed, writing "it is hard to keep up with all my teachers." Although the negative feelings about having multiple teachers and period were the minority, they are important to consider when exploring how the context of middle school affects student motivation and achievement. other Contextual Factors

Although friends and other students, classes, stress, and multiple periods are the primary contextual factors that 
appear to affect motivation and achievement, students also identified some other elements that either supported or discouraged them during their transitions to middle school. These other factors also influenced students' achievement by contributing to their motivation or leading to their disengagement. The food at both middle schools appears to be an overwhelmingly favorite. Many students wrote about the food on their surveys. Because they said there is a greater variety and the quality seems to be higher, the students consistently identified food as one of their favorite parts of being in middle school, although Mark suggested lowering the prices because he thinks it is too expensive.

Timing is another contextual factor influencing student engagement. Some students said that they would prefer if the school day started an hour later. When pressed, however, Jorge said that did not mean that he would want to go later in the afternoon, but Silvia thought that would be a worthwhile trade-off. She said that if school started later, "you would get more sleep and be ready for school and more rested." Survey respondents appeared to agree with Silvia. Lety said that "the worst part about middle school is starting at 7:45 in the morning," and Haley elaborated by saying that "it is hard to do good in school when I am tired."

Without changing the school day itself, students said that they would like a slightly longer morning break and lunch time. Sonia wrote on her survey that "we have the 
shortest lunch in the district," while TJ cited a more practical reality. "Brunch is too short. They don't have enough time to buy their snacks and stuff." Since friendship and peer support are important to young adolescents, they also use breaks and lunch to catch up with friends and meet their needs to be social, which Jamie said is a problem. "We don't have as much social time as we did, and they're stricter here. They've got more rules."

The physical environment also matters to students. Courtney enjoyed the library at her middle school because "it has heating and air conditioning, and I think it looks really new and nice. I like new things." Silvia agreed because she is allowed to use the library before school and during lunch to hang out or to type essays since she does not have a computer at home. On the other hand, many of the classrooms do not have heating and air conditioning, which affects the students' concentration. Courtney had trouble focusing when "they have to put on these big loud fans, and they distract me very much." Courtney also thought that "you shouldn't have to wear layers when you're going to school" which speaks to the importance of maintaining a constant temperature in the classroom.

Overall, the students made many specific comments about the physical, social, and emotional factors that created the contexts of their middle schools. By listening to their voices and exploring their stories, I began to understand 
how these contexts affect the students' motivation and achievement.

The Effects of Middle School Context

The students who shared their experiences through the surveys and interviews all described specific elements of the middle school contexts that affect their motivation and achievement. Sometimes the effects are positive in terms of fostering motivation while other times motivation is inhibited by certain components of the middle school context. As I began to understand the patterns that influence motivation and achievement, I also explored possible reasons that some adolescents are affected by context to a greater degree than others. An analysis of the students' stories suggests that the effects are mediated by extracurricular activities, influence from parents and friends, and students' feelings of competence or ability. Extracurricular Activities

Many of the students identified extracurricular activities as contributing to their motivation in school. The participant who chose the pseudonym of Kid wants to be on the surf team while in middle school and to earn a music scholarship while in college so he was concerned that his grades have been slipping, and he spoke at length about the effects of the slippage as well as the steps he is taking to improve them. "Well I made the surf team a couple months ago. We do competitions and we practice. . .right now I can't do any competition cuz I have to keep my grade up" 
(Kid). When Kid received his first progress report as a $6^{\text {th }}$ grader, he was happy with his grades. However, we spoke soon after the second progress reports were mailed, and Kid's grades had slipped considerably. When he realized that he may not be able to compete on the surf team, he began to attend a math tutorial after school in order to improve his grades. As he explained, "I'm catching up. . . the tutorial classes, just doing a lot of homework, getting it done. Spending more time, paying attention."

Many of the participants echoed Kid's sentiments when they spoke about extracurricular activities as being the impetus for their school motivation. Jorge said, "I go to this one Christian church, and I go like two times a week and that helped me to change my life," which has caused him to work more diligently in school. He thought that church has helped focus him so that he can concentrate on his work. In addition to church, Jorge enjoyed going to $6^{\text {th }}$ grade camp because "I met new friends and new people," and he saw different kinds of animals. Stacy liked the school dances, and Kid is involved with music and plays the drums in the school band. Mark's happiest memory of school is his participation in the school play because "it was fun to practice."

Not all of the students had positive comments about the status of the extracurricular activities however. Tom said that "the worst part about middle school is that they cancelled the funding for sports. Also there's not enough 
things to do at recess." When asked what would make middle school a better place to be, Kid responded that "they got good teaching standards, but to make it better, put in more activities, like more sports, after school programs. . .it's good for kids not to just go home, finish their homework, and just do nothing." As many of the students made clear, school needs to be more than just a place for academics and homework. Kid summarized many of the students' sentiments as he said, "If it depended on the learning, you'd try to get good grades to stay on whatever you're on. . because I find it (surfing) relaxes me, takes me away from everything." Because of the amount of stress that nearly all of the participants reported, extracurricular activities appear to provide a much needed release.

Parents

As dominant as extracurricular activities are in the participants' stories, an even more important influence on motivation and achievement appears to be the parents. Parents have a major impact on their children's desires to achieve. Some parents help children to "get good grades" (Mark) which encourages him to "work hard and get good grades." Similarly, Kelly is doing better academically in middle school than she was in elementary school because her mom has more time to help her with homework. Kelly thought the reason for the improvement is that "before she'd (Mom) have to work. Then I'd go off and do something else, and then I wouldn't have her check it and it'd be all wrong. . 
.she (Mom) explains it." Kelly's mom has also helped her learn how to manage her time which is important for middle school students to learn since, as was discussed earlier, multiple periods and teachers mean multiple assignments due at various times.

While Kelly and Mark gave examples of how their parents specifically and explicitly help them with their work, other participants commented on how the example their parents set influences their motivation. When parents care about grades, students are more likely to try to get good ones. Jorge does not care much about school, but he loves his mom, and she wants him to study hard so he does try, on occasion, to get good grades. He explained, "For me it (school) was just a game. I didn't care about my grades. . .but when my mom talked to me, cuz they were going to suspend me cuz I didn't do my homework and everything,. I do my homework now." If his mom did not care about his grades, Jorge said, "I'd be at home, not doing nothing." She helps him with his homework and reminds him that "if I don't want to work in Jack in the Box or something like that, to study and get a good job." The influence that Jorge's mom has on his motivation is not unique according to the other interview participants. Isabell's dad was a lawyer in Mexico, but he is not making much money here in the United States which she felt is due to his language difficulties. His experience makes her work more diligently in school. Her mom works a lot and does not make much money, and Isabell said that she does not want 
that to happen to her. Silvia's mom did not go to college and is currently unemployed. Silvia said that "my mom doesn't work, and she says that I should get into college cuz she didn't, and she regrets not going to college cuz now she doesn't have a job."

Another way that parents wield influence is through the morale boosts they provide to their children. Jamie's parents talk to her and make her feel better when she is stressed out. She said that her motivation comes from them. I'll talk to my dad, and it really does click. I don't know how but like it just makes me feel so much better. He doesn't like, he doesn't have to say anything. He just has to talk, just suddenly you feel so much better.

Jamie thought that other people may not be as motivated as she is because they may have a different level of support at home. "Maybe they don't have the same background as I do. Like, I mean you want to be able to succeed and stuff. So maybe their parents or their friends or whoever they hang out with don't make them want to do stuff." Survey respondents agreed as Jessica said, "MY parents also help by cheering me through school."

A few students offered reminders that parents are not the only positive family influence. Kid said that hanging out with his brothers helps him to "chill" so that he can stay focused at school because "like that's what me and my brother do." Silvia learned about middle school from her 
older sister so she knew what to expect which made the transition and adjustment much easier.

Although the majority of the students identified their parents or other family members as sources of support and inspiration, some also claimed that those sources hindered their motivation. TJ talked about his mom as detracting from his motivation to succeed in school. Because she pushes him relentlessly and does not allow him to make choices about how he will spend his time, TJ feels annoyed. "It's very annoying how my mom just says to do that (study). I tried telling her (that he needs some breaks), and she kept saying 'I want you in a good college so keep studying.' That's all she says." Even though TJ recognizes that his mom's support has helped him to be successful in school, he would like more balance in his life. "Probably every day she makes me study (this is in addition to attendance at Chinese school and lessons and practice for two different instruments). It makes me want to study less because I just want to play a few games whenever I feel like it." TJ does not want to get into the best college because his mom makes him study so much and has him involved in so many extracurricular activities. He feels "crowded" and would like more time for himself.

Competence

Students' motivation is also influenced by their feelings of competence. When students feel they are good at a task or activity, they are more likely to participate in 
it. When they experience success or know that they have the skills necessary to meet the challenges that middle school offers (Csikszentmihalyi, 1990), they seem to be less negatively affected by the contextual influences of middle school. TJ recalled a time when he was doing a science project correctly and not many other students were able to do it so they were watching him and asking him how to do it. "Not very many people were doing it right, and they saw that I was, and they were just laughing because they couldn't even do it. They were just watching me, and they were like 'how did you do that?' I like when people do that." On the other hand, "First isn't always good. . . so I don't really want to push the limits" (TJ). TJ's attitude could be a result of his mom pushing him without asking him what his goals are or what matters to him.

Jamie knows that she is a good student and sets goals for herself which pushes her to keep achieving even when other students tease her or when she is stressed out and overwhelmed. "I'm known as like the perfect student, but really like in my mind, I don't think that $I$ am. So I do feel awful when my friends tease me about it." Nonetheless, Jamie understands the importance of goal setting. "If you don't set goals for yourself, you'll always be having other people tell you this is what you need to know. If you set goals for yourself, then you know what you want to know, and it helps make it easier to remember." In his survey, Charles echoed Jamie's sentiments as he said "it makes me proud to 
see my good grades." Amy did as well because "school is important to me because whenever I do good in school, it makes me feel better about myself."

When students believe that they are academically capable, that knowledge is sometimes, but not always, enough to motivate them to achieve. When Isabell receives poor grades, she said that it makes her feel bad. "I see how some people feel really bad when they get bad grades. Then if they try their best and just can't do it, and I can do it, so I should work." Kid's feelings are internally located, but he feels the same way. He said "not getting good grades just puts me down. It like makes you want to get better grades, like I could have done better. I look back, and I think how I could have done better to get a better grade." Some external sources also influence the students' feelings of competence. In spite of his rebellion against his mom's pressure, TJ said "I just like being successful" because he watches television programs about people who graduate from high school and college. Silvia engages in some friendly competition with her sister because "I just want to do good in school and like impress my sister." As long as the students feel confident in their competence, dips in their grades appear to be temporary.

When students do not feel competent, their achievement is more negatively impacted. Since Jorge does not feel that his English is very good, he does not like science because the words are difficult to understand. His discomfort with 
English also makes school a distasteful place much of the time. As he already mentioned, if it were not for his mother's support and encouragement, he would most likely not do any work at all. Even when external incentives like ice skating trips are offered, Jorge's motivation is not consistent. He said that he wants to be able to participate in the trips, but if he is tired, he still will not do his homework.

Students also compare themselves to their classmates. If their perceived abilities do not measure up, motivation suffers. Courtney explained,

Math is easier for me because I'm on the same level as the other kids in my class. And so I think that like that's better because some people do really bad in math and some people do really good in math. But then I feel like some people are worse than me in math, but in English I feel like I'm the worst one. Feeling like the worst one makes Courtney much less likely to engage. She said that she enjoys and works diligently in math class but does not engage much in English. She wants to impress her classmates and repeats that if she does not perceive that she knows as much as everyone else in the class, she will stay very quiet and severely restrict her participation.

Based on student verbal and written reflections, however, it appears that students' feelings of competence are not limited to academics. Young adolescence is a time of 
hormone surges and heightened awareness of both sexuality and independence, and these feelings pervade many of the students' waking thoughts. Although many of the participants commented on these feelings, one of the survey respondents poignantly expressed the sentiments of many of her peers. Judy is worried about her image. "I am sometimes really mean. I feel really bad about being mean to people, but I'm afraid if I don't act or look tough, then people will bully me." At the same time, however, she is worried about finding love. "I've always worried about having a boyfriend. Not once in my life have I ever been asked out. Most of my friends have had at least two boyfriends."

\section{Influence of Teachers}

While the students' stories demonstrate that the context of middle school influences their motivation and therefore achievement in both positive and negative ways, it is also clear that the teachers themselves appear to play a significant role in the creation of these contexts. The survey responses (Table 5) indicated that most students felt positively about having multiple teachers but did not often engage with their teachers outside of the classroom. Through the way they teach during class, interact with students, and convey their expectations, teachers influence their students' desires to engage in or disengage from the school learning experience. 
Teaching Practices

The students in the study identify specific techniques that their teachers employed to make learning fun and authentic or boring and irrelevant. According to Silvia, using manipulatives in math is fun, and it also helps students remember content. Standing up, chewing gum, using hand movements, anything that allows the students to be more active are also mentioned as practices that contribute to the students' engagement in class as well as to their ability to understand and remember content. If teachers spend too much time just talking in class, the students "get bored and distracted" according to Lety. "Playing games" makes learning more fun and encourages Mark to get more involved in his classes. Kid echoed Mark's sentiments, and he elaborated to say that "the really good teachers, they have really good methods to teach. Like they make the kids understand. . .like games and they're really clear." When the teachers ask if the students have questions before they go $(\mathrm{Kelly})$, the students feel as if their learning matters. Teachers who understand the adjustments that the students need to make as they transition to middle school and who take the time to explain concepts clearly are appreciated by the students, as is evidenced by Silvia's comment. "They showed me around the school. The first day we talked about what we'd learn in our classes, and we did like activities to remember where our classes were. We had to walk around the school." Many of the students acknowledge 
the positive feelings that are created by teachers who ensure that they understand the new concepts. Kelly said, "I think my teachers in middle school just explain it better." Jorge agreed, saying, "They're like good teachers because they show you good. You learn more. It makes it easy to do it (work) because they don't just go 'here's your paper, do it.' They show us some problems that we don't know how to do."

Not all teachers, however, engage in the positive behaviors that students identify as contributing to their learning. Jamie said that "the teachers don't make it easier for you like in elementary." When teachers "make everybody stand up in front of the class and answer" (Courtney), many students disengage from learning. Courtney said it is because "I'm kind of like an outgoing person usually, but when I have to stand in front of the class, I like get really nervous, and I don't like that." As a result, she chooses not to participate in the classes where oral presentations are not preceded by scaffolding and support. Based on survey and interview responses, Courtney's sentiments are not isolated. It appears that the students do not mind participating in class, but they do not want to be singled out or have too much attention placed on them. When teachers help their students see how class concepts can be used in the real world and build on previously learned information so that each day is connected to the previous and subsequent ones (Jamie), the students 
appear to be much more motivated. On the other hand, "memorizing dates and names without a purpose" makes class boring (Silvia), which appears to lead to disengagement. Specific teaching practices influence the way that the teachers interact with their students, and both contribute to the participants' motivation and desire to engage. Interactions with students

As with the actual teaching practices, students gave examples of ways that the teachers interact with them that either foster or inhibit motivation. Even if the students did not like a particular class, they sometimes felt motivated to engage if the teacher interacted with them in certain ways as will be discussed below.

Fostering Motivation

Even though she does not like fitness days in PE, Kelly likes her teacher because he is funny and continually checks for understanding. "He always asks if we have a question. He asks us before we go" (Kelly). He also jokes around with the students, which increases their comfort level and desire to participate. Silvia's science teacher also uses humor to relate to her students "because she uses a whole bunch of weird words we haven't heard about. She talks weird." Silvia likes that because she feels the relaxed behavior makes her teacher more approachable. TJ agreed as he described his band teacher. "He's funny because we get him to do a lot of things that are funny." 
The students made it clear, however, that they are not solely interested in teachers who make them laugh. They want to be treated with respect, and they want to learn. On her survey, Kelsey said that "the best part about middle school is they don't treat you like babies," which is a thought that is repeated in various forms by many of the survey respondents and interview participants. Isabell, the student who appreciates that the "psychos" that permeate her cousin's middle school are not at Willow Glen, said the difference between the two schools is the teachers. My cousin says that the teachers at her school are really mean and sometimes they cuss. They don't do that here. People here respect the teachers. They teach you when they say no it means no. When they say something you have to do, you do it. And they tell you when they're kidding and when they're not kidding. When Jorge's teachers are "cool and show you how to do things," he appreciated the opportunity to learn and to improve his English.

Inhibiting Motivation

Not all of the teachers interact with their students in ways that foster motivation. When teachers yell, the students are much more likely to disengage from those particular classes. Jorge said, "In science sometimes she screams at us when she gets mad at other persons or something. Sometimes she's bad." As Jorge mentioned in his other statements, science is a difficult subject for him 
because of the English barrier, and the combination of the two causes him to put it low on his priority list. When he is tired, he will choose sleep over his science homework. He also tends to misbehave and disrupt his science class. Other teachers attempt to motivate their students through fear, which appears to have the opposite effect, as Jamie explained.

The teachers aren't really the ones who motivate you. Sometimes they scare you. They tell you all these things that you're going to need in eighth grade, and that puts more pressure on you. . .that's not very good motivation cuz it might cause kids to do a worse job cuz they're so afraid they're going to get a bad grade. Jamie articulated a feeling that many of the students expressed through both their surveys and interviews. Feeling scared and worried did not contribute to sustained motivation. In fact, TJ also worked from a fearful place, and he thought that trying to get into the best college might cause him to "pull a muscle like when you're competing against someone who is better than you."

Conveyed expectations

When the teachers "expect their students to do really well" (Kelly), the participants said they are much more likely to participate in class. This participation often leads to sustained engagement and higher academic achievement. On his survey, Kid said that the best part of middle school is "having good teachers who care about my 
education," and he elaborated during his interview. "I got good teachers, all good teachers. They care about their job, and they like make sure we can understand everything." When asked how he knows that they care about their jobs, Kid said "because some of the teachers are funny, but they can be strict like to get us to learn it."

Students' comments repeatedly illustrated that they are not looking for easy teachers who do not make them work. Instead, the students want teachers who care about their learning, make their high expectations explicit, and provide the support to achieve those expectations. When teachers are clear about their expectations, Isabell said she is more likely to respect them. Jamie said she appreciated teachers who support her but always demand that she exert her best effort. The students recognize that when "they make sure that I have everything, that I don't forget anything" (Isabell), the teachers are making it clear that they expect students to succeed. These expectations convey a clear message to students about who cares for them and their success and who does not. Kid explained that "if they didn't care about the students, they wouldn't try to teach them. . .then I wouldn't enjoy going to school as much. Class would be more boring."

While most of the students had more positive than negative comments to make about the way that their teachers conveyed high expectations, some of the participants also 
had disturbing stories to tell. Courtney described one of her desires.

I guess you're really not going to find a teacher who wants to sit and work with you in middle school. That's one of the things that I miss from elementary school. . - They knew you better. But these teachers, they don't like care if you do well or not. They're just there to teach you, and if you choose to learn that's not their problem.

As the other students made clear, this is not what they want. They want the teachers who do care whether or not the students choose to learn.

Courtney also explained how when one of her teachers plays favorites, the motivation of the entire class is inhibited. "She says, 'Oh Wendy (another student), you're one of my strongest writers. I'll save that one for Wendy.' So I'm kind of like jealous of Wendy." Courtney likes the class content and wants to succeed, but she is continually frustrated that her teacher does not believe that she can perform at the same level as Wendy. Her grade in the class is low because she does not like doing the work anymore. Because she does care about her achievement, however, Courtney stayed after school to earn extra credit. During that experience, she got to know her teacher a little better which has improved her attitude toward the class in general. "I never really thought of her as a real person. . . I think it's better for her if some kids understand her better." 
Students in this study continually reflect a desire to feel connected to their teachers while also wanting to know that their teachers expect them to work diligently and think them capable of high achievement.

\section{Observations of the Context}

As I discussed in chapter three, my observations of four students during the regular school day represent an additional data source. The observations supplemented stories students told during the interviews and on the surveys, and they confirm many of the beliefs, attitudes, and perspectives the students self-reported. There are four days of observation of the students during classes and at break times. I have sampled the field notes here in order to reflect the confluence of their self-reports and the behavior I observed. The sampling is purposeful because the intent of the study is to highlight students' voices reflected in their self-reports, not the behavior apparent in their social interactions.

These observational data appear at the end of chapter four because students' actions often do not match their self-reported feelings, beliefs, or needs. The middle school years are a time of searching for many young adolescents. As they move from childhood to adulthood, they strive to become independent and search to find identity, often a messy, tumultuous, even ambiguous process. As Jamie said in the interview, "I want to impress these people," and Judy wrote on her survey, "I feel really bad about being mean to 
people." Because middle school students' choices and behaviors do not consistently match their self-reported motives, teachers must be careful not to focus on external actions and miss altogether what is going on internally with their students. I have highlighted students' self-reports because those are the more authentic windows into what drives them.

Interactions with teachers

While following kid, I noticed that the way that he felt about teachers affected his behavior in class and his engagement on assignments. After being reprimanded for not following directions in one class, he muttered under his breath, "You're always picking on me." The teacher heard him and kept him after class to have a conversation. She said that she was not picking on him, and she was sorry that he felt that way. When she apologized, Kid's body language relaxed visibly, and he appeared to be much more willing to talk about solutions to their conflict. This small interaction appeared to support Kid's repeated comments that his teachers cared about their jobs and wanted their students to do well in school.

During her lunch break, Isabell went back to one of her classrooms in order to talk with the teacher about make-up work. The teacher was responsive, giving Isabell the missing assignments and praising her for being responsible and coming in on her own time. While Isabell was talking with the teacher, several other students came into the class, 
ostensibly for similar reasons. I was struck by the ease with which the teacher related to his students and how he made them feel comfortable when they approached him for extra help.

Although I witnessed Isabell and Kid's positive interactions with their teachers, I also observed a class that confirmed what some of the survey respondents and interview participants said about not wanting to engage with teachers who yelled at them. One teacher in particular appeared to manage the class primarily through fear and spent the majority of one class period yelling at the students to stop talking, to put their feet flat on the floor, and to keep their backpacks out of the aisles. As this was Jorge's class, I watched him closely, and he appeared to disengage more and more as the period progressed. His posture slumped, his head drooped, and he did very little work. By the end of the period, Jorge had laid his head upon the desk and was not even attempting to appear engaged.

Relevance

Another contextual element that I found emphasized repeatedly during my observations was the importance of relevance in student engagement. During one of Jamie's classes, the teacher was having the students listen to a book on tape and follow along in their own texts. Jamie appeared not to be interested at all in the story and whispered continually to the person sitting next to her. It 
sounded as if they were discussing their plans for the upcoming weekend. Since Jamie participated in many of her other classes, it appeared that she chose not to engage when the class content did not outweigh her more immediate needs. Friends

Throughout the interviews and surveys, students expressed the need to be with their friends and to impress their classmates and peers. The importance of peer relationships was borne out during the observations as well. In classes and during the less structured times of lunch and passing periods, the students used every opportunity to socialize. For example, the presence of a new student caused a commotion during math class. During small group work time, the students sitting around her asked for her schedule and vied to demonstrate their knowledge of the school and the teachers. Many of the boys appeared to find the new arrival attractive and spent much of their "work time" flirting and trying to get her attention. When the teacher called the attention of the class back to the front of the room, many students appeared reluctant to refocus on math, but eventually everyone did. It was clear that the desire to get to know the new student far outweighed the importance of the math lesson.

In another class, I noticed an opposing tendency. Although I was observing Isabell, my attention was drawn to another student because of the way he carried himself and worked throughout the class. He sat in the last desk in the 
last row and did not utter a word, to students or the teacher, during the entire period. For the most part, he kept his eyes on the overhead when the teacher was teaching and then focused on his book and assignment during independent class time. Even when all of the other students were talking and joking with each other, this student did not participate. I felt that his behavior supported what many of the interview participants felt when they spoke about needing to impress their classmates and feeling insecure in classes where they did not know anyone.

Teachers are only able to view their students' external actions. Unless teachers take the time to get to know their students, they will not see what is going on internally because students will not allow this more intimate view. Nevertheless, the observational data in this study supported the students' stories and lent strength to the benefits of building strong teacher-student relationships.

Summary

During Courtney's interview, she had difficulty answering one of my questions. After stumbling over her words, she finally said, "Nobody's ever asked me that before." We talked a little about that response and then continued with the interview. Courtney's answer resonated with me throughout the data analysis and writing that followed the interviews. Why am I the first person to ask her about her school experiences? Why are teachers, administrators, and politicians missing out on the rich 
stories that the students have and are willing to share? Her statement is the "so what?" of this study.

The students revealed, when asked, that they have clear and specific ideas about what contextual factors motivate them and encourage them to achieve. Friends and other students, their interactions with teachers, the relevance or lack thereof of their classes, and the stress that they experience on a daily basis all contribute to their motivation and achievement. These factors are mediated by the extracurricular activities in which they are involved, the varying levels of parental and family support, and their beliefs about their competence. Although the factors are diverse and challenging, they point to specific steps that educators can take to create motivating learning environments for all students.

The following chapter will discuss lessons learned from listening to students' stories. Based on those lessons, it will also identify recommendations for educators to consider when they are working to create motivating learning environments, as well as identify potential avenues for further research. 
Chapter Five

Discussion

Through surveys and interviews, this study involved sixth and seventh graders in their beginning months as middle school students. To understand how young adolescents perceived their transitions from elementary to middle school and to explore how their experiences affected their desire to engage in school learning experiences, I encouraged the students to tell me their stories honestly. The students included girls and boys, Caucasians and Hispanics, and sixth and seventh graders. In spite of their widely-varied life experiences, their stories were remarkably similar. The themes woven through their stories provide powerful insights for teachers trying to improve their own practice by creating more motivating learning environments for young adolescents.

How I Came to this study

When I began my journey as a teacher, I taught kindergarten in East Los Angeles. Even though my students primarily came from poor families who did not have much in the way of material comforts, and many did not speak English as a first language, they were all eager and excited to come to school every day. I did not have to fight them to engage or worry about ways to get them interested in their learning. On the contrary, my primary problems stemmed from the need to teach the children how to function as part of a learning community and to control their excitement at times 
in order to allow everyone a chance to participate. When I moved to sixth grade at the middle school in the same community, however, everything changed. Engaged and excited students were the exception, and apathetic or angry students were the norm. What had happened along the way to compromise their enthusiasm for learning?

These questions remained with me as I moved to a different district in a different county and taught ninth grade in an alternative school for students who had not met academic exit criteria to attend comprehensive high schools. These new students were angrier and more apathetic than my sixth graders. They were even further removed from the joyful kindergarteners I remembered from my first year. Again I wondered what had happened to compromise their excitement about learning. My work with sixth and ninth grade students, the belief that they were reachable if I could find the right entry point, my academic studies, and numerous professional conversations worked together to lead me to this study. I have long believed that if educators value the voices of the students we teach, we can learn to work in concert with them to meet both their needs as unique individuals and the needs of a large educational system that is responsible to the public. Listening to the voices of the middle school students in this study strengthened my belief that every child is reachable. Every child has limitless potential. Their stories suggest ways to unlock their potential. 
Why it Matters

Discourse is a way of thinking, acting, and using language that identifies an individual as a member of a specific group (Gee, 1999). Young adolescents devote much of their waking energy to finding social groups with whom they want to identify. Although many adults have blunted the emotional trauma that comes from being rejected by the "cool crowd," middle school students will rarely voluntarily engage in any task or experience that marks them as different or as not belonging. Gee's work (1991, 1999) on discourses allows researchers and educators to understand this very real phenomenon of young adolescence through a different lens. This lens seeks to understand how the contexts in which people find themselves influence the choices they make and the perceptions they have, which might lead to a better understanding of how external factors influence internal feelings.

Because participation in dominant discourses usually leads to the acquisition of social goods and power (Gee, 1991), it is not surprising that most young adolescents work so diligently to ensure that they are accepted into that discourse. When the students are second language learners or come from homes that do not value the same tasks, goals, or experiences that schools value, they are at an even greater disadvantage. They are engaged in two tasks: navigating the nearly universal turmoil of young adolescence as well as 
understanding and adapting to the social and cultural norms of a different discourse.

If educators are sensitive to the unique needs of each of their students, they create environments where all students are successful-even those who do not come from homes that operate within the dominant discourse. Regardless of the quality of a school or a classroom, "non-mainstream children will always have more conflicts in using and thus mastering dominant discourses" (Gee, 1991, p. 10). Gee's work helps educators understand that we must learn how to help non-mainstream children develop mastery over the skills that the dominant discourse values so that it cannot be used as a gatekeeper to limit their accomplishments.

Finally, Shernoff and his colleagues (1999) found that "there appears to be a sharp and distinct decline in student engagement that occurs between sixth and eighth grades" ( $p$. 43). The quantitative nature of their study does not explain why this decline occurs or what steps can be taken to reverse it, but it does suggest that teachers' and parents' anecdotal stories are borne out in quantifiable data. Because this current research built on the work of Shernoff, et al and talked to the students themselves, this study provides insights into possible reasons behind the decline in engagement. The students in this current study provide suggestions for their teachers that can be used in the design of motivating learning environments. 
After thinking about what the participants' stories mean to educators, I have identified four ways of thinking about how teachers can create motivating learning environments in their classrooms. I call these ways of thinking the four lessons learned from the participants in this study who shared their stories so honestly. The rest of this chapter is devoted to a discussion of these lessons learned. Based on the data, it appears that students are perfectly able to articulate what they need and want from their environments in order to navigate the new and unfamiliar realm of adolescence. Embedded within the lessons are implications for educators as they consider their goals and make plans for subsequent school years.

Each sub-section that follows identifies a lesson learned from this study's participants, offers student quotes, observations, existing research, and my own experiences to support the identified lesson, and suggests specific strategies for teachers to employ when creating motivating learning environments.

Lessons Learned

\section{First lesson}

The first lesson that the participants in this study taught is that relationships with peers and trusted adults form the bedrock from which students succeed or fail. The students in this study repeatedly emphasized that their desires to engage in school were often directly tied to the relationships that they had with their parents, friends, and 
teachers. Although I was struck by the expressed importance of parental relationships in the students' stories, I do not think that students without supportive parents are doomed to failure or disengagement. What matters to students is that someone in their lives understands who they are and cares about what they do, and teachers can meet that need if the parents do not.

In addition to parental influence, teachers also contribute to students' desires to engage in school learning experiences. Courtney said that her elementary school teachers "knew you better," but her middle school teachers "don't care if you do well or not." Whether or not Courtney's statement is an accurate representation of her teachers' feelings, this belief influenced her desire to engage in school. In my experiences teaching young adolescents, I have learned that students' beliefs about their teachers affect many of their behavioral and academic choices. I have had numerous conversations with students to explain that I do like them and am not picking on them. Regardless of what I say, however, each of my past students needed to form their own judgments. When I tell a student that his/her perception is not accurate, I am only met with resistance. When my actions support my words, however, I can often find a way to connect with most reluctant learners. In Courtney's situation, she talked about how the support her parents provided made her feel important and encouraged her to engage in her classes. On one of the surveys, Jessica 
wrote that her parents "help by cheering me on through school."

Not all students had parental relationships that contributed to their success, however. TJ said that his mom "orders me around. . . I just don't like being ordered around. She pushes the limit on me. She does too much." Even though he emphasized that his mom negatively affected his desire to engage in school, his grades and participation demonstrate that he is still achieving at fairly high levels. TJ attributed his high achievement to his teachers. They care about him, joke with him in class, and work to make sure that he and all students are learning.

It appears that as long as students have at least one trusted adult-whether parent or teacher-in their lives, they are more inclined to engage in school. The students' perceptions echoed what Lumsden (1994) said, "If students experience the classroom as a caring, supportive place where there is a sense of belonging and everyone is valued and respected, they will tend to participate more fully in the process of learning" (p. 3). Conversely, I found that students in an earlier study (Daniels \& Arapostathis, in press) demonstrated that they will not participate at all if they do not feel valued and respected.

Parents and teachers are not the only individuals with whom young adolescents form trusting relationships. When teachers recognize that peer relationships can be more important to middle school students than almost anything 
else, those teachers are more likely to work in concert with their students' needs. Silvia said that she likes "coming to school and talking with my friends." Amy wrote on her survey that "when I'm with my friends, I always feel happy and alert." Jorge's initially turbulent adjustment to life in the United States was eased as he "got more friends." These statements represented many of the students' attitudes toward their peers. Friendships matter significantly and can provide students with reasons to engage in school if they do not have strong relationships with either their parents or their teachers. The importance of friendships was also borne out during the time I spent at the middle schools. Small groups of students could be found clustered together during free times. Many students whispered to each other and passed notes during class if they were not interested in what the teacher was saying.

Although middle school students place an emphasis on forming peer, teacher, and parent relationships, teachers should not lower their expectations for behavioral or academic achievement. "Since standards have been adopted, schools, and urban schools in particular, have felt pressured to focus on standards rather than on students as they plan instruction" (Storz \& Nestor, 2003, p. 18). In order for teachers to develop positive, supportive relationships with their students, they must focus on the students' needs, desires, and interests as they plan 
instruction that will bring students to mastery of the standards.

Allowing students to interact with teachers on a personal level increases teachers' ability to form the relationships that positively influence engagement.

Courtney, who did not like her journalism teacher, said she got to know the teacher a little better when she stayed after school on two occasions. As a result, she said, "I felt closer to her. I think it's better for her if some kids understand her better." The first lesson learned from the middle school students and discussed in this section leads to some very specific implications for teachers.

Implications

If teachers work to develop relationships at the same time they are designing strong instructional activities, there will be a better possibility of encouraging their students' engagement and usually achievement in school. Some strategies for developing stronger teacher-student relationships are as follows:

- Make a concerted effort to get to know every studenthave them write in journals and read/respond, greet them at the door, listen to their conversations during passing periods, pay attention to their body language, let the students into the classroom before and after school.

The information that is learned through these formal and informal interactions will help teachers better understand 
who they are teaching. When a student acts to disrupt class or quietly slumps in his/her seat, an involved teacher may know why. This knowledge can lead to interactions that are focused on the actual problem as opposed to the surface symptom.

- Value what students bring to school-incorporate their personal interests into the curriculum; do not belittle what they want to do; acknowledge their decisions even if they may differ from the decisions we, as their teachers, would want them to make.

Although it is difficult for caring teachers to stand by and watch students make mistakes, those students must be allowed the freedom to be right and the freedom to be wrong. This is not to say that teachers should ignore or condone decisions which hurt the students themselves or others around them. What it does mean is that making decisions and facing the consequences of those choices are critical growth experiences that are part of the maturation process.

Young adolescents crave the freedom to be in control of their lives and will seek to exert that control whether or not schools provide such opportunities. By valuing what students bring to school, teachers create environments where young adolescents learn to balance their increasing needs for autonomy with experiences in healthy decision-making. When teachers see their students making what may be viewed as poor decisions, those teachers should work with the students to help them understand both sides of the issue or 
to realize that they do have a choice. If the students persist in making a poor decision, then the teacher must help them face and deal with the consequences of that decision without condemning them.

All students bring unique interests and talents into the classroom, but if they are made to feel that those interests are not valued, then their motivation suffers. If . a student makes a decision that an adult would not have made or is interested in a topic in which an adult might find nothing of value, the teacher's response influences subsequent motivation and desires to engage. Being caring and non-judgmental does not mean allowing students to make excuses for poor behavior or lazy work habits. It means that teachers hold students responsible for the consequences of their actions while helping them understand the distinction between making a poor choice and being a "bad person." By providing the safety net of a caring, non-judgmental relationship, teachers have a better chance of being allowed to guide students through the tumultuous years of young adolescence.

- Support their friendships-allow friends to sit next to each other in class; allow them to choose their own groups when appropriate to your curricular purposes; if you notice inappropriate relationships developing, talk with your students, do not condemn them.

students rely heavily on their networks of peer support. When they do not fit in or cannot find a group with whom 
they click, their self-concept suffers. "Self-concept is the descriptive perception of self in terms of one's various roles and attributes" (Lipka, 1997), and self-esteem is the positive or negative value that people place on their perceptions (Lipka, 1997). When middle school students do not have social groups with which they identify, their selfconcept suffers as they tend to perceive themselves as less worthy or desirable than their peers. When students have low self-concept, a decrease in their self-esteem often follows because they place a negative value judgment on their perceptions of self.

Teachers who work with these deep-seated adolescent needs instead of against them save time and emotional energy, which can be devoted to instruction. If students are not making good choices in terms of who they sit next to in class, teachers can and should intercede. Otherwise, students will usually demonstrate that they can make good choices as long as they are given the opportunity to do so. second lesson

The second lesson that I learned from the participants is that teachers convey their beliefs about their students through their speech and practice, which profoundly influences students' desires to engage in school learning experiences. The second lesson learned from students in this study is both empowering and overwhelming. In spite of the many contextual factors of young adolescents' lives that are outside of any teacher's control, teachers profoundly 
influence their students' motivation by the expectations that they hold and the manner in which those expectations are conveyed. I found this lesson to be empowering because it reminds me that teachers are not helpless when it comes to encouraging students to achieve. It is also overwhelming, however, because it emphasizes the importance of our role in the classroom and in our students' lives. This finding echoes those of the few researchers who have chosen to speak directly with the students they study. "What appears to set some teachers apart as motivators is their ability to transcend institutional roles in favor of a more personal approach to teaching" (Csikszentmihalyi, Rathunde, \& Whalen, 1993, p. 181).

As I analyzed the survey and interview data, I found that students want to know that their teachers think they can achieve. If students know that their teachers believe in them, then they want to be challenged academically and those same students want their teachers to explicitly teach. When teachers explicitly teach, they prepare lessons in advance, model new problems, and discuss new concepts instead of merely assigning chapters to be read or worksheets to be completed. When Courtney's teacher repeatedly told her class that one student in particular was the strongest writer of the group and thus, as Courtney said, "she always gets to do everything," that teacher sent a powerful message about her expectations for the rest of the class. On the other hand, Kid felt that his teachers "care about their job because 
they get us to learn." During each of my years in the classroom, I experienced the power of expectations. I always had a few students who were amazed at their progress by the end of the school year. One of my mantras was that "you can do anything you set your mind to," and many of the students demonstrated the power of this statement.

After spending time in one of Jorge's classes for this study, I noticed the impact that teacher expectations have on student engagement as could be observed by behavior and body language. Jorge's teacher made at least three negative, or somewhat negative, comments to or about her students. She reprimanded the students for poor behavior without pointing out the several students who had been compliant. She mentioned to a visiting teacher that "you can't trust the kids" to do what is right. She also announced that the current class could not do the assignment as well as her other classes. I found it difficult to sit quietly and listen to these comments, and I was saddened by the way that some students physically withdrew by looking away or putting their heads down, and other students actively defied the teacher by shouting out, talking to each other, or refusing to work.

If teachers expect students to learn, they will learn (Stipek, 1988). Students are extremely intuitive when it comes to identifying which of their teachers hold high expectations for student achievement. Teachers can and should explicitly encourage risk-taking with learning. This 
means that teachers show students how to learn from mistakes and how to build success out of past failures. Instead of viewing a low grade or a poor performance as something to be punished, motivating teachers show students what went wrong and offer specific strategies to improve in the future. With this approach, students feel comfortable with risking more difficult assignments because they know that they will receive the support and feedback necessary to improve. When teachers encourage risk-taking in their classrooms, they build a caring community of learners, and the students will participate because they feel that their contributions are valuable (Oldfather, 1994). This creates a positive cycle of authentic engagement leading to increased achievement. When teachers are vigilant about communicating their expectations and listening to what students want, students will often respond by working to live up to those expectations. As with the first lesson learned, this lesson leads to specific implications for teachers' actions both during and outside of class time.

Implications

- Be aware of unconscious beliefs and attitudes-do not make assumptions about any student; allow students the opportunity to make up for past mistakes.

Students will live up or down to the expectations their teachers have for them. When fair consequences are administered consistently, students will begin to see that each of their actions and choices leads to either positive 
or negative outcomes. This puts students in control of their behavior and learning and ensures that their past behaviors will not dictate their future choices.

- Differentiate curriculum-use multiple assessments to identify specific learning needs; provide support and scaffolding based on those unique needs; allow students multiple paths to the same outcomes.

Students do not feel more motivated when teachers tell them they are doing well. Students' self-esteem changes when they feel competent and in control of their abilities. Telling students that they are good people or are doing well does not mean that they will feel better about their abilities. Instead, students feel better about themselves (self-esteem) when they have a clear perception of their strengths and weaknesses (self-concept). When teachers do not shy away from telling students that they have fallen short of expected achievement and provide specific and immediate feedback about subsequent steps to take, they convey the expectation that every student can achieve. Instead of holding lower expectations for struggling students, motivating teachers provide more support so that they can all achieve at high levels.

- Body language and facial expressions convey expectations-eye rolls, sighs, and crossed arms send powerful messages about our feelings toward and our beliefs about students. 
Although teachers are prone to the same frustrations and disappointments as everyone else, they must be vigilant about how they react to frustrating students or undesirable behavior. When teachers maintain a calm demeanor and administer both positive and negative consequences judiciously, they send a message that all students are expected to achieve and that all students will be held accountable for their choices and actions.

- Monitor the ways in which teachers talk about our students-as teachers, we must be vigilant about the ways in which we talk about students in the faculty lounge or hallways; motivating teachers must understand that offhand comments and careless remarks linger in students' minds and psyches.

Negative beliefs and comments often translate into unconscious actions that may send signals to students that we do not think they can achieve. If students have not formed the strong relationships discussed in the first lesson, those young adolescents may not be able to overcome the debilitating effects of low teacher expectations. Third lesson

The third lesson learned from students in this study is that young adolescents need to be given emotional support and to be taught specific strategies to learn how to cope with the increased amounts of stress in their lives. The participants in this study emphasized the increased amount of stress that they encountered once they transitioned to 
middle school. While not completely unexpected, the ubiquity and severity of the stress was my most surprising finding. TJ poignantly articulated the feelings of many of his peers. "It's like you're in a parking lot, and everyone's pushing against you. All that work I'm doing, it's pushing against you. It makes me feel very heavy-headed. I feel crowded." When young adolescents face tremendous amounts of stress without a commensurate increase in support, they are less likely to develop their talents (Csikszentmihalyi, Rathunde \& Whalen, 1993) and are more likely to feel that they are not autonomous, or not in control of their own lives (Deci, Koestener, \& Ryan, 2001). If students do not feel autonomous or have little or no control over their choices and actions, they are much less likely to want to engage in school-learning experiences because not participating is one way of exerting the control that most young adolescents crave.

Jamie said, "It's (homework) way too much. It's way overwhelming. It's stressing kids out, and it's not gonna make them do better." Jamie also reminded teachers that merely assigning more work will not motivate students or increase their achievement. Her comment supports my thinking that feeling overwhelmed by school discourages some students from even attempting work because they believe they are inadequate before they begin.

Feelings of not being in control also arise when students do not feel competent or do not think that they 
possess the skills necessary to successfully meet challenges that school offers. "Students are likely to become discouraged with tasks that make them feel incompetent, especially in classroom settings where failure is publicly visible" (Shernoff et al, p. 8). These feelings of incompetence or inability to achieve school tasks are exacerbated during young adolescence when students are also struggling to find a place for themselves in the social world of middle school. They are less likely to take risks with their learning because, as Jamie said, "I want to impress these people."

However, if teachers work with students "in developing strategies for coping with failure and persisting with problem-solving efforts when they experience difficulties" (Brophy, 1998, p. 3), students will feel that they are in control of their successes and failures. This, in turn, leads to greater motivation and increased achievement. Effective teachers demonstrate their belief in their students' abilities through words and actions. Instead of getting angry at students' shortcomings, effective teachers provide specific strategies that students can employ in order to improve the quality of work or to perform more effectively on school tasks. When students feel they are valued because of who they are or what they bring to the, learning experience, they are more inclined to participate in difficult assignments (Daniels \& Arapostathis, in press). The likelihood of engagement increases because students do 
not feel pressured to maintain control by projecting either an image of infallibility (by performing flawlessly) or nonchalance (by not trying, thus not succeeding).

I believe that the second and third lessons learned are closely connected because teachers' beliefs about their students appear directly to influence the likelihood that they will be sensitive to students' stress and explicitly teach coping strategies.

Implications

- Teachers should be honest about the demands of real life-share pieces of their own lives with students; be honest about their stressors; teach specific coping skills that they have learned through the years. For example, model how to write assignments and tasks in planners or calendars, demonstrate how to organize time in order to accomplish all required work, and brainstorm activities that students can pursue as breaks from the stress of homework or family responsibilities.

Although I did not observe any examples of teachers sharing coping strategies with their students in this study, my own experiences in the classroom as well as the students' stories during the interviews led to this recommendation. Through eight years of teaching young adolescents, I noticed that when I acknowledge students' worries, fears, and stresses, they are more likely to engage in my lessons. Generally, students do not want to be coddled or excused 
from work; they want to be taught how to deal with increasing amounts of stress. Young adolescents want to know that their teachers have also been through turmoil and have found ways to persevere and succeed.

When young adolescents hear about events or experiences that cause stress in their teachers' lives, they begin to realize that they are not alone. Because of the transition from the egocentrism of childhood to the groupcenteredness of adolescence (Perlstein, 2003), middle school students often feel that they are the only ones being picked on, experiencing stress, or facing a dilemma. Teachers who feel comfortable sharing minor or significant examples of their own stressors help to break down feelings of isolation. By offering specific coping strategies, motivating teachers place control back in their students' hands and encourage their feelings of autonomy. By providing examples of perseverance and determination, motivating teachers demonstrate that stress and frustration are not debilitating and that success is a possible, even likely, outcome of an initial failure.

- Be empathetic-honor students' feelings and worries; listen to what the students are going through; either acknowledge their feelings and/or concerns or suggest specific advice depending on which action is more appropriate.

Whenever students share either insignificant or substantial problems, they are demonstrating trust in their teachers' 
ability and desire to help them. Telling students that their stomach aches are unfortunate, but the school nurse will not be able to help takes no more time than telling students that they do not have a stomach ache or getting angry. Even if teachers cannot offer solutions to the problem or issue, they prove themselves worthy of students' trust when they offer empathy and advice as opposed to scorn and derision.

- Collaborate with other teachers-identify when major tests are scheduled or substantial assignments are due; spread them out so that students are not faced with the crushing pressure of several major assignments or tests in a short period of time; help students see connections across subject areas and disciplines which may make their studying more efficient.

Sometimes it is impossible to avoid a "crunch time." If so, be honest with the students. When they know that their teachers understand that a given week will be very stressful, students may feel less resentment. By teaching them time management skills or stress relief techniques, motivating teachers remind students that they are in control of the decisions they make and the reactions they have to any given event. Being sensitive to the stress in students' lives does not mean coddling them or not challenging them. It simply means sharing the coping strategies that we adults have learned through years of experience. 
Fourth Iesson

The fourth lesson learned from the participants in this study is that relevance matters. Middle school must mean something to young adolescents immediately-not just be a preparation for some distant future. The students overwhelmingly emphasized that school needs to matter for them immediately. Being told that they would need to know something for high school or when they are adults did very little to foster their intrinsic motivation because high school and adulthood exist in a distant future and do not possess the urgency that daily concerns pose. As Silvia said, "Science is less important than the rest of the things because I don't really think I'm going to need science like the other things. Math, I'm going to need it a lot when I grow up." Teachers need to consider how the content of their classes connects to their students' experiences outside of school (Shernoff, et al, p. 48). Middle school participants in another study explained that "figuring things out, fixing things, and making things" all helped connect students to their immediate school experiences (Smith \& Wilhelm, 2002, p.124). I watched many students over the years "tune out" or refuse to participate if I could not present an immediate and/or relevant need to engage in any given task.

When five-year-olds begin school as kindergarteners, they are enthralled by the whole experience of learning. Primary teachers and parents of young children generally agree that their children's motivation is not difficult to 
ignite. Many successful adults have kept this enthusiasm for learning or enjoyment in what they do, which could be an explanation for why some people are motivated to persevere through challenges. "The main reason they (talented people) do what they do is because they enjoy it" (Csikszentmihalyi, Rathunde, \& Whalen, 1993, p. 8). When teachers take the time to learn about their students' interests (Lesson \#1) and clearly convey that they expect students to achieve (Lesson \#2), they create contexts that foster internal motivation. In such environments, the need to avoid mistakes or the appearance of failure gives way to a willingness to take risks with their learning and to strive to reach their full potential. As with the first three lessons learned, the fourth lesson suggests specific approaches that teachers may take as they work to create motivating learning environments.

Implications

- Reassess homework-think critically about the types of homework that are assigned; question its relevance and connection to content standards; collaborate on assignments with other teachers so that students can work smarter, not harder.

Motivating teachers ask themselves critical questions about the homework they assign. Is it absolutely necessary or is it just a time-filler? Does it serve a specific instructional purpose and move students forward in their academic progress? Will students be able to complete it in a 
reasonable amount of time and independently if they do not have home support? All of these considerations can and should be addressed in order to make homework a meaningful part of students' academic lives.

- Ensure that homework and class work connect to students' interests or immediate needs-find out what students are interested in; connect the curriculum to those interests; again, collaborate so that students can work on one large assignment for three teachers instead of numerous disconnected tasks.

If the content standard dictates that students will learn how to write research reports, and a student has a passion for aviation, let that student study the history of airplanes in order to write the report. Teachers can teach the same research skills to a class of students who are studying many different topics. When teachers remember that the assignment or project is simply the vehicle through which mastery is demonstrated, they find ways of increasing the relevance of their curriculum and instruction.

- Find authentic audiences-invite community members to watch presentations; ask students to write letters to the editor and actually send them; search for contests or other venues that highlight student work. Not surprisingly, the students in this study grew tired of writing and performing solely for their teachers. When an essay will only be read by the teacher, or a presentation will only be viewed by the class, students lose sight of the 
relevance of their work. If a persuasive essay will be read by the editor of the local newspaper, the importance of correct punctuation and spelling is more urgent. If a student's math ability will be evaluated by a potential employer, successful performance on the chapter test becomes more applicable to his/her daily life. It is possible that not every minute of every school day will immediately connect to every young adolescent. However, when teachers and schools make relevance one of their driving concerns, the students in this study suggested that their internal motivation would be positively influenced.

\section{Summary of Lessons Learned}

The intent of this study was to solicit the stories of middle school students and to demonstrate the need to privilege students' voices in discussions on motivation and achievement. I believe that the participants' stories demonstrate that young adolescents are both willing and able to share their experiences as they navigate the tumultuous arena of middle school. The stories suggested answers to the research questions that drove this study and provided lessons for teachers to reflect on as they design motivating learning environments.

In summary, the lessons learned from the sixth and seventh graders in this study are:

1) Relationships with peers and trusted adults form the bedrock from which students succeed or fail. 
2) Teachers convey their beliefs about their students through their speech and practice which profoundly influences students' desires to engage in school learning experiences.

3) Young adolescents need to be given emotional support and to be taught specific strategies to learn how to cope with the increased amounts of stress in their lives.

4) Relevance matters. Middle school must mean something to young adolescents immediately-not just be a preparation for some distant future.

Although these lessons learned are not easily implemented, they provide a starting point for educators who want to teach students how to deal with numerous external pressures in order to ensure that internal motivation is not impeded by factors beyond an individual's control.

The first research question that drove this study asked what was in the context of middle school that affects earned achievement and the desire to engage in school. The lessons the participants taught me suggest answers to the question. Friends and other students, the relevance or lack thereof of classes, and stress caused by homework or other commitments are all contextual factors that influence the internal motivation of middle school students. These factors affect some adolescents and not others (second research question) because of varying levels of family support as well as the students' individual beliefs about their competence. Finally, teachers play an enormous role in the creation of 
motivating, or not motivating, learning environments (third research question) by the way they interact with their students and convey beliefs about student abilities.

By thinking about and taking the participants' stories to heart, teachers will be better equipped to create learning environments that foster the motivation of all students. Educators will be richer if they are truly willing to listen to the unfiltered, honest voices of their students.

\section{Suggestions for Future Study}

Although this study illuminates key elements that contribute to or detract from the motivation of middle school students, it also raises many more questions. These questions are to be expected in a study that explores people's attitudes, perspectives, and emotions, and the participants' stories suggest avenues for further research that will continue to illuminate paths that educators can take in order best to meet the diverse needs of all students.

"Eventually it will be necessary to understand the experience of school in the larger context of family, peers, work, and extra-curricular activities" (Shernoff, 1999, p. 49). This study builds on the work of Shernoff and his colleagues by exploring the experiences of students in the context of school in order to understand how those contexts affect their motivation. Future research should continue exploring the effects of external factors on internal 
motivation in order to clarify how students' school experiences influence their engagement in the larger world. Studies that explore the differences in how engaged and disengaged students function outside of school-at home, in sports, or during extracurricular activities-may provide additional insights into their needs and desires.

This study identified numerous contextual elements that influence students' desires to engage. Additional studies could expand the perspective used here by looking at how expectations from elementary and high school teachers and administrators affect decisions that are made at the middle school level. By looking at the contextual elements that exist at a system-wide level, researchers may identify additional insights into the external factors that influence students' internal motivation.

Finally, this study highlights the experiences of nine middle school students in one small town. By replicating the methods used here in other towns and in larger studies, researchers may find support for the universality of the participants' experiences or may uncover other lessons learned that will continue to inform teachers as they create motivating learning environments for all students.

Conclusion

Most educators enter the field because of a profound desire to do what is right for children. They work diligently day after day in order to ensure that students engage in learning experiences that are designed to help 
them access the skills necessary to become responsible, contributing, and productive members of the global society. Although, as in any field, there are exceptions to these statements, I came to this study out of a desire to learn more about creating motivating learning environments in order to improve my own practice and possibly enhance the practice of my colleagues.

The motivation paradigm that has driven education for decades focuses on external factors such as rewards and punishments that will encourage students to work more diligently to achieve in school. Changing this paradigm to focus on the factors that support internal motivation will not happen easily, but it is imperative, as the participants in this study repeatedly stated. Teachers cannot make students motivated, but they can create environments that increase the possibility of students feeling motivated to engage in school. 


\section{References}

Au, K. (1997). Literacy for all students: Ten steps toward making a difference. Reading Teacher, 51(3), 186-194.

Alspaugh, J. (1998). Achievement loss associated with the transition to middle school and high school. The Journal of Educational Research, 92(1), 20-25.

Amrein, A., \& Berliner, D. (2002). High-stakes testing, uncertainty, and student learning. [Electronic version]. Education Policy Analysis Archives, 10(18). Available: http://epaa.asu.edu/epaa/v10n18.

Amrein, A., \& Berliner, D. (2003). The effects of highstakes testing on student motivation and learning. Educational Leadership, 60(5), 32-38.

Anderman, L. \& Midgley, C. (1997). Motivation and middle school students. In J. Irvin (Ed.), What current research says to the middle level practitioner (pp.41-48). Columbus, OH: National Middle School Association.

Bakhtin, M. (1989). Dialogic imagination: Four essays. Austin, TX: University of Texas Press.

Bandura, A. (1991). Self-regulation of motivation through anticipatory and self-reactive mechanisms. In $R$. Dienstbier (Ed.), Perspectives on motivation (pp. 69-164). Lincoln, NB: University of Nebraska Press.

Berube, M. (1996). The politics of national standards. The Clearing House. 69(1), 151-3.

Brophy, J. (1998). Failure syndrome students (Report No. EDO-PS-98-2). Washington, D.C: Office of Educational 
Research and Improvement. (ERIC Document Reproduction Service No. ED419625)

Bruner, J. (2002). Making stories: Law, literature, life. New York: Farrar, Strauss, \& Giroux.

Charmaz, K. (2000). Grounded theory: objectivist and constructivist methods. In N. Denzin \& Y. Lincoln (Eds.), Handbook of qualitative research, second edition (pp. 509536). Thousand Oaks, CA: Sage.

Cole, M. (1996). Cultural Psychology: A once and future discipline. Cambridge, MA: Harvard University Press.

Collins, N. (1996). Motivating low performing

adolescent readers. (Report No. RR93002011). Washington, D.C: Office of Educational Research and Improvement. (ERIC Document Reproduction Service No. ED396265)

Clandinin, D., \& Connelly, F. (2000). Narrative inquiry: Experience and story in qualitative research. San Francisco: Jossey-Bass.

Covington, M. (1992). Making the grade. New York: Cambridge University Press.

Creswell, J. (1998). Qualitative inquiry and research design: Choosing among five traditions. Thousand Oaks, CA: Sage.

Csikszentmihalyi, M. (1990). Flow: The psychology of optimal experience. New York: HarperPerennial.

Csikszentmihalyi, M. (1996). Creativity: Flow and the psychology of discovery and invention. New York: HarperPerennial. 
Csikszentmihalyi, M., Rathunde, K., \& Whalen, S. (1993). Talented teenagers: The roots of success and failure. New York: Cambridge University Press.

Cushman, K. (2003). Fires in the bathroom: Advice for teachers from high school students. New York: The New Press.

Daniels, E., \& Arapostathis, M. (in press). What do they really want: Student voices and motivation research. Urban Education.

Davydov, V. (1998). A new approach to the interpretation of activity structure and content. In Chaiklin, S., Hedegaard, M., \& Jensen, U. (Eds.). Activity theory and social practice: Cultural-historical approaches. Aarhus: Aarhus University Press.

DeBlase, G. (2003). Acknowledging agency while accommodating romance: Girls negotiating meaning in literacy transactions. Journal of Adolescent and Adult Literacy, $46(8), 624-637$.

Deci, E. (1995). Why we do what we do. New York: Penguin Books.

Deci, E., Koestner, R., \& Ryan, R. (2001). Extrinsic rewards and intrinsic motivation in education: Reconsidered once again. Review of Educational Research, 71(1), 1-26. Deci, E., Vallerand, R., Pelletier, L., \& Ryan, R. (1991). Motivation and education: The self-determination perspective. Educational Psychologist, 26(3), 325-346. 
Doherty, L., \& Mayer, D. (2003). Email as a 'contact zone' for teacher-student relationships. Journal of adolescent and adult literacy 46(7), 592-600.

Dweck, C. (1985). Intrinsic motivation, perceived control, and self-evaluation maintenance: An achievement goal analysis. In C. Ames \& R. Ames (Eds.), Research on motivation in education (pp. 289-306). Orlando, FL: Academic Press, Inc.

Dweck, C. (1991). Self-theories and goals: Their role in motivation, personality, and development. In $R$. Dienstbier (Ed.), Perspectives on motivation (pp.199-236). Lincoln, NB: University of Nebraska Press.

Dweck, C. (2000). How Can Teachers Develop Students' Motivation and Success? Education World. Retrieved March 8, 2001 from http://www.education-world.com

Eccles, J. \& Wigfield, A. (1997). Young adolescent development. In J. Irvin (Ed.), what current research says to the middle level practitioner (pp. 15-30). Columbus, $\mathrm{OH}$ : National Middle School Association.

Erickson, F. (1984). School literacy, reasoning, and civility: An anthropologist's perspective. Review of Educational Research, 54(4), 525-546.

Erickson, F. (1987). Transformation and school success. Anthropology and Education Quarterly, 18(4), 335-356.

Erickson, F. (1992). Ethnographic microanalysis of interaction. In M. Lecompte, W. Millroy, \& J. Preissele 
(Eds.), The handbook of qualitative research in education.

New York: Elsevier Science \& Technology Books.

Fair Test and Massachusetts CARE. (2000). MCAS: Making the Massachusetts dropout crisis worse. Retrieved January 9, 2004 from

http://www. Eairtest.org/care/MCAS:20Alert\%20 Sept.html.

Fichtner, B. (1998). Activity revisited as an explanatory principle and as an object of study-old limits and new perspectives. In S. Chaiklin, M. Hedegaard, \& U. Jensen (Eds.), Activity theory and social practice: Cultural-historical approaches. Aarhus: Aarhus University Press.

Finders, M. (1996). Just girls: Hidden literacies and life in junior high. New York: Teachers' College Press. Gee, J. (1991). What is literacy? In C. Mitchell \& $\mathrm{K}$. Weiler (Eds.), Rewriting literacy: Culture and the discourse of the other (pp. 3-12). New York: Bergin \& Garvey.

Gee, J. (1999). An introduction to discourse analysis: Theory and method. London: Routledge.

Gee, J. \& Green, J. (1998). Discourse analysis, learning, and social practice: A methodological study. In P. Pearson \& A. Iran-Nejad (Eds.), Review of research in education (pp. 119-169). Washington, D. C: American Educational Research Association.

Gratz, D. (2000). High standards for whom? Phi Delta Kappan, 81(9), 681-7. 
Hedegaard, M., Chaiklin, S., \& Jensen, U. (1998). Activity theory and social practice: An introduction. In S. Chaiklin, M. Hedegaard, \& U. Jensen (Eds.), Activity theory and social practice: Cultural-historical approaches. Aarhus: Aarhus University Press.

Hinchman, K., Alvermann, D., Boyd, F., Brozo, W., \& Vacca, R. (2003/2004). Supporting older students' in-andout-of-school literacies. Journal of Adolescent and Adult Literacy, 47(4), 304-311.

Johnson, D. \& Johnson, R. (1985). Motivational processes in cooperative, competitive, and individualistic learning situations. In C. Ames \& R. Ames (Eds.), Research on motivation in education (pp. 217-248). Orlando, FL: Academic Press, Inc.

Jones, M. \& Gerig, T. (1994). Silent sixth grade students: Characteristics, achievement, and teacher expectations. The Elementary School Journal, 95(2), 169-182.

Kohn, A. (1993). Punished by rewards: The trouble with gold stars, incentive plans, As, praise, and other bribes. Boston: Houghton Mifflin.

Lewis, A. (1995). An overview of the standards movement. Phi Delta Kappan, 76(10), 745-50.

Lincoln, Y. (1995). Emerging criteria for quality in qualitative and interpretive research. Qualitative Inquiry, $1(3), 275-290$.

Lipka, R. (1997). Enhancing self-concept/self-esteem in young adolescents. In J. Irvin (Ed.), What current research 
says to the middle level practitioner (pp. 31-40). Columbus, OH: National Middle School Association.

Lumsden, L. (1994). Student motivation to learn. (Report No. OERI RR93002006). Washington, D.C: Office of Educational Research and Improvement. Retrieved September 7, 2000 from

http: //www. eric. uoregon. edu/publications/digests/digest092.h tml.

Marshal1, C. \& Rossman, G. (1989) . Designing qualitative research. Newbury Park, CA: Sage.

Maxwell, J. (1996). Qualitative research design: An interactive approach. Thousand Oaks, CA: Sage.

McCombs, B. (2002). Understand the keys to motivation to learn. Retrieved December 2, 2002, from http: / / www.mcrel.org/products/noteworthy/noteworthy/barbaram asp.

McPhail, J., Pierson, J., Freeman, J., Goodman, J., \& Ayaapa, A. (2000). The role of interest in fostering sixth grade students' identities as competent learners. Curriculum Inquiry, 30(1), 43-70.

Mercado, C. (1998). When young people from marginalized communities enter the world of ethnographic research: Scribing, planning, reflecting, and sharing. In A. EganRobertson \& D. Bloome (Eds.), Students as researchers of culture and language in their own communities (pp. 69-92). Cresskill, NJ: Hampton Press, Inc. 
Mizelle, N. \& Mullins, E. (1997). Transition into and out of middle school. In J. Irvin (Ed.), What current research says to the middle level practitioner (pp. 303316). Columbus, OH: National Middle School Association. Moje, E. B. (2000). "All the stories that we have:" Adolescents' insights about literacy and learning in secondary school. Newark, DE: International Reading Association.

Neill, M. (2003). The dangers of testing. Educational Leadership, 60(5), 43-46.

National Middle School Association. (2003). This we believe: Successful schools for young adolescents. Columbus, $\mathrm{OH}$ : Author.

Oldfather, P. (1994). When students do not feel motivated for literacy learning: How a responsive classroom culture helps. Athens, GA: University of Georgia (ERIC Document Reproduction Service No. ED365966)

Pace, B. (2003). Resistance and response: Deconstructing community standards in a literature class. Journal of Adolescence and Adult Literacy, 46(5), 408-411.

Palincsar, A. (1998). Social constructivist perspectives on teaching and learning. Annual Review of Psychology 49(1), 345-376.

Perlstein, L. (2003). Not much just chillin: The hidden lives of middle schoolers. New York: Farrar, Straus, and Giroux. 
Perry, S. (1999). Writing in flow. Cincinnati, OH: Writers' Digest Books.

Polkinghorne, D. (1988). Narrative knowing and the human sciences. Albany: SUNY Press.

Seidman, E., Allen, L., Aber, J., \& Feinman, J. (1994). The impact of school transitions in early adolescence on the self-system and perceived social context of poor urban youth. Child Development. 65, 507-522.

Shernoff, D., Schneider, B., \& Csikszentmihalyi, M. (1999). The quality of learning experiences in American classrooms: Toward a phenomenology of student engagement. Manuscript submitted for publication to the American Journal of Education.

Smith, M., \& Wilhelm, J. (2002). Reading don't fix no chevys: Literacy in the lives of young men. Portsmouth, NH: Heinemann.

Stake, R. (1995). The art of case study research. Thousand Oaks, CA: Sage Publications.

Stake, R. $(2000)$. Case studies. In N. Denzin \& Y. Lincoln (Eds.), Handbook of qualitative research, Second edition (pp. 435-454). Thousand Oaks, CA: Sage Publications.

Stetsenko, A. (1998). Social interaction, cultural tools, and the zone of proximal development: In search of a synthesis. In S. Chaiklin, M. Hedegaard, \& U. Jensen (Eds.), Activity theory and social practice: Cultural-historical approaches. Aarhus: Aarhus University Press. 
Stevenson, C. (2002). Teaching 10 to 14 year olds, third edition. Boston: Allyn and Bacon.

Stipek, D. (1998). Motivation to learn: From theory to practice. Boston: Allyn and Bacon.

Storz, M. \& Nestor, K. (2003). Insights into meeting the standards from listening to the voices of urban students. Middle School Journal. March, 2003.

Strauss, A. L., \& Corbin, J. (1998). Basics of qualitative research: Techniques and procedures $f$ or developing grounded theory, second edition. Thousand Oaks, CA: Sage.

Strong, R., Silver, H., \& Robinson, A. (1995). What do students want (and what really motivates them)? Educational Leadership. Retrieved March 8, 2001 from http: / /www.middleweb.com/StdntMotv.html.

Taylor, S. \& Bogdan, R. (1998). Introduction to qualitative research methods. New York: John Wiley \& Sons, Inc.

Thompson, S. (2001). The authentic standards movement and its evil twin. Phi Delta Kappan, 82(5), 358-62.

United States Department of Education. (1992). Hard work and high expectations: Motivating students to learn. Retrieved March 22, 2001 from http: //www.kidsource.com/kidsource/content $3 /$ work. expectation s.k12.4.htm1.

Valencia, S. \& Wixson, K. (2000). Policy-oriented research on literacy standards and assessment. In M. Kamil, 
P. Mosenthal, P. Pearson, \& R. Barr (Eds.), Handbook of reading research, Volume 3 (pp. 909-935). New Jersey: Lawrence Erlbaum Associates.

University of Chicago. (2004). Retention policy fails to improve low-performing students' achievement and increases dropout rates. Retrieved April 7, 2004 from http://www. news.uchicago.edu/releases/04/040407.retention.sh $\operatorname{tm} 1$

Vygotsky, L. S. (1978). Mind in society. Cambridge, MA: Harvard University Press.

Wertsch, J. (1991). Voices of the mind: A sociocultural approach to mediated action. Cambridge: Harvard University Press.

Zhu, N. (2001). The effects of teachers' flow experiences on the cognitive engagement of students. Unpublished doctoral dissertation, University of San Diego, San Diego. 


\section{Appendix A \\ Definition of Terms}

Accountability: Teachers and students have clear standards for learning and must demonstrate that learning through various forms of assessments.

Context: Speech, actions, and expectations that exist in any situation or environment.

Cultural models: Theories or storylines used by people to assimilate new information in order to construct meaning about their experiences or from their surroundings (Gee \& Green, 1998) .

Externally enacted motivation: Engagement in an activity because of the expectation of reward or because of pressure from other sources.

High stakes assessments: Use of test scores to make decisions that have important consequences for individuals (www .eplc.org/mpearlman . html) )

Internally generated motivation: The desire to engage in activities because of the pleasure inherent within and without expectation of tangible rewards.

Semiotics: Cultural artifacts such as language, gestures, numbers, and other symbol systems that hold meaning for people in a community (Cole, 1996; Wertsch, 1991).

situated meanings: Understandings that are constructed "onthe-spot" based on cues in the phrasing such as tone, stress, and pause (Gee \& Green, 1998). 
Sociocultural theory: The belief that mental functioning and human development are mediated (influenced) by social, cultural, and institutional factors (Wertsch, 1991).

Standardized tests: Exams created by publishing companies that are tested for validity and reliability and administered to large groups of students at a time. Normreferenced tests are scored by comparing a student's performance to a group of his/her peers against which the test was measured. Criterion-referenced tests are scored according to the test taker's performance on each item. 


\section{Appendix B}

\section{Summary Profile of Kid}

Kid has had a difficult time adjusting to middle school, but his extracurricular activities have helped him to enjoy it more. "Like I'm on the surf team, so when I surf, I'm happy cuz I'm with all my friends." He is very interested in and committed to surfing and music. They are also helping him to focus on goals for his future. "I want a music scholarship and get to a higher level in school and do band. Cuz I'm in band right now, and I wanna like just improve my music like skills. My cousin, his name's Ben, goes to UCLA. He got a music scholarship, playing tuba. He got a full scholarship. Yeh, I kinda want to do what he did." Those activities are keeping him focused on achieving in school because he understands that he needs to keep his grades up in order to participate in surfing and band. To get a music scholarship he needs to "I think just stay in band and keep grades up. I think you have to pass like certain tests, in drumming, take tests, but they're not like big tests." Surfing allows Kid to both spend time with his friends and relax which is important because of the added stress that middle school. "I find it (surfing) relaxes me, takes me away from everything. I'm just out on the water."

Kid's grades have slipped since entering middle school which he thinks is because he tends to lose focus. Since his grades are tied to participation in surfing and band, he is working to improve them. "I'm doing like this math tutorial; 
that's helping me just bring my grade up. . . I wanna stay on the surf team. Right now I can't do any competition." Although he has gotten behind in school, he says "I'm catching up" and he credits "the tutorial classes (and) doing a lot of homework, getting it done. Spending more time, paying attention" with his improving grades. He also understands that he has the ability to be successful even when he isn't, and it makes him feel badly when he doesn't achieve to his full potential. "It like makes you want to get better grades, like I could have done better. I look back, and like I think how I could have done better to get a better grade." He would like it if school placed more of an emphasis on extracurricular activities because he thinks it would provide a good balance with academics. "They got good teaching standards, but to make it better. . .put in more activities, like more sports, after school programs. . .cuz it's good for kids not to just go home, finish their homework, just do nothing."

The teachers at middle school care tremendously about their students which Kid appreciates "They care about their job; and they like make sure we can understand everything," and he recognizes that he wouldn't like school as much if they were not as good. "I wouldn't enjoy going to school as much. Yeh, like class would be more boring, like I wouldn't enjoy it." Kid thinks that the teachers are relaxed and fun, but they also know when to be strict and make sure that the students are learning. "They like make sure we can 
understand everything. Some of the teachers are funny, but they can be strict like to get us to learn it." By playing games and explaining information clearly, the teachers ensure understanding, and "they have really good methods to teach. Like they make the kids understand." All in all, the teachers create an environment that makes Kid happy to come to school. "It's not boring; it's like I don't not like it. $\dot{I}^{\prime} m$ just coming to school and being with friends and doing like all the stuff I like." 


\section{Appendix C}

\section{Initial Information survey}

1. How important to you is doing homework?

Very important. . . Kind of important. . Not important at all

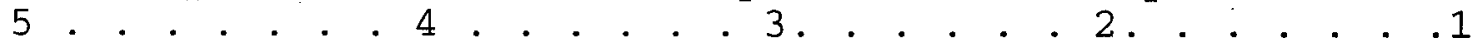

2. How often do you participate in school activities that do not occur during the regular school day?

Always. . . . . . . . . . Sometimes. . . . . . . . . Never

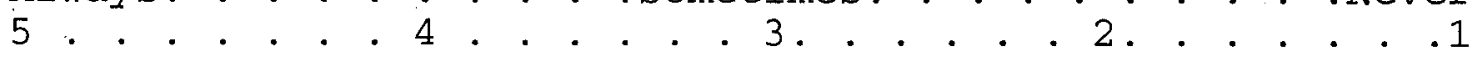

3. When you are in class, how well do you concentrate on the lessons?

Very well. . . . . Pretty Well . . . . Not well at all

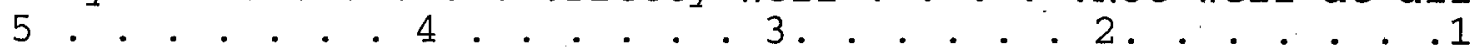

4. How often do you participate in class discussions?

All the time. . . . . . . Sometimes. . . . . . . . . Never

5...... 4 . . . . 3... . . 2. . . . 1

5. How often do you volunteer to read aloud?

All the time. . . . . . . . Sometimes. . . . . . . . . Never

5......4...... . . . . . 2...... . . 1

6. How often do you talk to teachers outside of class?

Frequently. . . . . . . . . Sometimes. . . . . . . . . Never

5...... 4 . . . . . 3... . . 2. . . . 1

7. How do you feel about having several teachers?

Very good. . . . . . . . Okay. . . . . . Not good at all

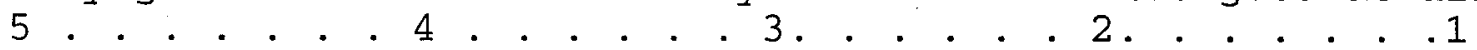

8. How much of what you do in your classes are you interested in?

Everything . . . . . Some things. . . . . . . . Nothing

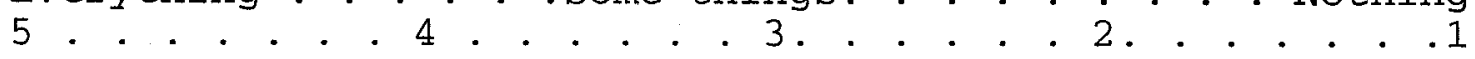

9. Describe your usual mood while you are at school.

Alert. . . . . . . . . . Okay. . . . . . . . . . . Tired

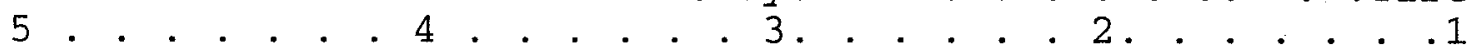

Happy . . . . . . . . . . Okay . . . . . . . . . . . Angry

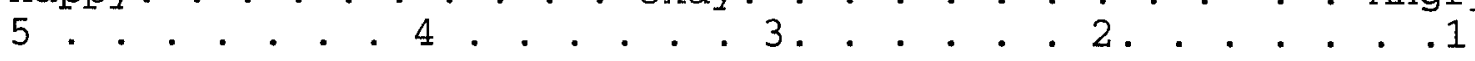

10. What is the best part about middle school? The worst part? 
11. Is doing well in school important to you?

12. If so, why? If not, why not?

If you would like to provide more information about any of your answers, please do so here: 


\section{Appendix D}

\section{Interview Protocol}

Tell me about a time when you felt happy about school.

Tell me about a time when you felt unhappy about school.

Is doing well in school important to you? Tell me more about that answer.

What do you like best about your new middle school?

What is the worst part about your new middle school?

How do you feel about your teachers?

Do you feel as if you are an achiever or not an achiever?

If you were in charge here, what would you change about your middle school? What would you definitely want to stay the same? 